\title{
1 Combined wave and surge overtopping erosion failure model of 2 HPTRM levees: accounting for grass-mat strength
}

3

Saiyu Yuan ${ }^{1}$, Hongwu Tang ${ }^{2 *}$, Lin $^{2} i^{3}$, Yi Pan ${ }^{4}$, and Farshad Amini ${ }^{5}$

${ }^{1}$ Assistant professor, State Key Laboratory of Hydrology-Water Resources and Hydraulic Engineering, Hohai University, Nanjing, 210098, China. E-mail: yuansaiyuhhu@gmail.com

${ }^{2}$ Professor, State Key Laboratory of Hydrology-Water Resources and Hydraulic Engineering, Hohai University, Nanjing, 210098, China (Corresponding author).E-mail: hwtang@hhu.edu.cn

${ }^{3}$ Associate professor, Department of Civil and Environmental Engineering, Jackson State University, Jackson, Mississippi, 39217, USA. E-mail: lin.li@jsums.edu

${ }^{4}$ Assistant professor, College of Harbour, Coastal and Offshore Engineering, Hohai University, Nanjing, 210098, China. E-mail: panyi21hhu@gmail.com

${ }^{5}$ Professor and Chair, Department of Civil and Environmental Engineering, Jackson State University, Jackson, Mississippi, 39217, USA.E-mail:famini@jsums.edu

\section{ABSTRACT}

High performance turf reinforcement mat (HPTRM) has emerged as an effective and flexible strengthening system to protect earthen levees against the erosion caused by overtopping flows. The purpose of this study is to characterize the erosion and failure processes of HPTRM-strengthened levees under combined wave and surge overtopping. The Erosion Function Apparatus (EFA) is used to analyze the erodibility of HPTRM-strengthened clay. The erodibility parameters such as critical shear stress and erodibility coefficient are then obtained. A HPTRM-element model is proposed to account for the mechanism of HPTRM in protecting cohesive soil with the help of EFA results in the characterization of the grass mat strength parameter. At last, a failure model is developed based on the excess stress equation, and the durations of HPTRM-strengthened levees against combined overtopping with different wave heights and freeboards are presented.

\section{Keywords:}

Combined storm surge overflow and wave overtopping, high performance turf reinforcement mat, EFA, failure model, levee

\section{Introduction}

Hurricanes and typhoons are normally accompanied by storm surges and extreme waves that may cause overtopping of coastal structures, such as levees, dikes, and seawalls. Wave overtopping can lead to a significant erosion or even complete destruction of the levees, and thus endanger the lives and property close behind them, as was the case during Hurricane Katrina in 2005, Hurricane Sandy in 2012, and Typhoon Haiyan in 2013. Hurricane Katrina caused a loss of about 1300 lives and $\$ 100$ 
billion in the City of New Orleans (Briaud et al., 2008), Hurricane Sandy caused a loss of about 120 lives and $\$ 500$ billion in New York and New Jersey (Yuan et al., 2014b), and the death toll of Typhoon Haiyan was more than 6,190 in Philippines alone. The failure of the New Orleans levees during Hurricane Katrina has been attributed primarily to the overtopping and seepage (ASCE, 2007). The erosion failure occurred first on the land side of the overtopped levees, where the flow velocity and erosive force were significantly higher than the flood side during the combined wave and surge overtopping (van der Meer et al., 2009; Figure 1a). Thus, the crest and landside slopes at risk of overtopping are preferably protected with some type of strengthening method, such as turf reinforcement, hard armoring and soil strengthening, to resist the erosion of the fast-flowing and turbulent water overtopped the levee crest (Briaud et al., 2008; Pan et al., 2012; van der Meer et al., 2009; and Sills et al., 2008).

The high performance turf reinforced mat (HPTRM) has emerged as a flexible strengthening system for crest and landslide slopes of earthen levee. It uses a three-dimensional (3D) matrix of nylon filaments with high tenacity polyester geogrid reinforcement at low strains to lock soil in place, and provides permanent reinforcement to prevent soil loss during storm events (Kelley and Thompson, 2008). It is light-weight and has about $95 \%$ open space (Figure 1b). As the grass sward grows through the HPTRM, the roots entwine with the mat to form a reinforced turf capable of withstanding the hydraulic lift force and shear force caused by the overtopped flows (Figure 1c). Thus, HPTRM can be used as a vegetated slope reinforcement system that consists of a rolled-out geosynthetic composite material integrated with natural grass (Goodrum et al., 2011).

[Figure 1 near here]

Although extensive studies have been conducted on the steady flow overtopping of levees (e.g., surge overflow and broad-crest weir outflow; Hughes et al., 2008, Bosman et al., 2007, Nelsen et al., 2005), there are very few studies on the hydraulic and erosion characteristics of levees under combined wave and surge overtopping, which is the most dangerous overtopping condition (Hughes and Nadal, 2009; van der Meer et al., 2009; Pan et al., 2012; Yuan et al., 2014ab). Hughes and Nadal (2009) conducted a 2D laboratory study on the combined wave overtopping and storm surge overflow of a levee in a $0.91 \mathrm{~m}$-wide wave flume at a nominal prototype-to-model length scale of 25 to 1 , and provided empirical formulas for average overtopping discharge, mean flow thickness, and mean velocity. A full scale wave overtopping simulator was developed by van der Meer et al. (2009) to perform the destructive tests on the landside slopes of levees in order to establish the erosion resistance against overtopping waves from severe storms. The performance of HPTRM-strengthened levees under combined wave overtopping and storm surge overflow were studied by Pan et al. (2012) and Yuan et al. (2014a), in which data of 3D velocity and flow thickness were collected, and hydrodynamics, turbulence, and erosion processes were investigated. The hydrodynamics at the toe of landside levees has been a central concern of many studies, where the flow velocity and turbulence is high, flow thickness is small, and the erosion is greatest. However, it is difficult to measure the supercritical overtopping flow and turbulent shear stress at that place due to the limitations of physical scale or experimental equipment. A 3D hydrodynamic model was used to predict the flow structure of HPTRM-strengthened levee against storm surge overflow and combined overtopping with different freeboards and wave heights by Yuan et al. (2014bc). New equations for turbulent shear stress and 
1 erosion rate at the toe of landside slope were developed. However, the complex water-soil-HPTRM

2 interface and unsteady overtopping flow caused by random waves make it difficult to determine the

3 exact mechanism of HPTRM to resist the erosion, as well as failure process and duration of the

4 HPTRM-strengthened levees under combined surge and wave overtopping.

5 The purpose of this study is to characterize the erosion and failure processes of

6 HPTRM-strengthened levees under combined wave and surge overtopping. Note that failure here

7 means that HPTRM loses its ability to protect the levee slope, rather than the total destruction of the

8 whole levee. Erosion Function Apparatus (EFA) is used to obtain site-specific erodibility data of

9 HPTRM-strengthened clay such as the critical shear stress and erodibility coefficient. Its results are used to update Turf-element model developed by Hoffmans et al., (2008) with grass strength replaced by grass-mat strength. The updated model could account for the mechanism of HPTRM in protecting cohesive soil. At last, a failure model is developed based on the excess stress equation, and the durations of HPTRM-strengthened levees against combined overtopping with different wave heights and freeboards are presented.

\section{Background}

\subsection{Erosion and failure of hydraulic structures with or without protection}

Ralston (1987) in his study of embankment erosion distinguished between cohesive and non-cohesive soils and the characteristic erosion of each. For cohesive soil embankments, erosion begins most commonly with a small headcut near the toe of the dam, and then the headcut advances upstream by hydrodynamic forces as well as soil loss until the crest of the dam is breached. The mechanics of headcut erosion causing breach of an earth spillway were discussed in detail by Temple (1989). Powledge et al. (1989b) classified the embankment into granular or cohesive fills according to the overtopping erosion performance, and showed that erosion often started at the embankment toe during turbulent erosion and propagated upstream, undercutting the slope, causing large chunks of material to be removed by soil tensile and shear failure on the over-steepened slope. Singh (1996) showed that dam could fail gradually or suddenly, depending on the cause of failure and the type of dam. However, most earth dams fail gradually, and the assumption of sudden failure is not tenable in general. Based on the observation of full-scale embankment experiments, Hahn et al. (2000) indicated that overland sheet flow from the downstream crest overtopping initiated rill and microrill erosion on the downstream slopes of the embankments first, and resultant erosion caused the development of a network of rills which gradually developed into a master rill(s) (i.e., gully) through crossgrading and micropiracy. Visser (1998) and Zhu (2006) described the levee failure process in clay dikes by assuming an initial breach in the top of the trapezoidal-shaped clay dike..

Extensive research has been conducted to quantify the performance of grass in embankment and steep waterway (Chen and Anderson, 1987; Hewlett et al., 1987; Temple et al., 1987; Powledge et al., 1989ab; Muijs, 1999; Hanson and Temple, 2001; Hoffmans et al., 2008; Steendam et al., 2009; and van der Meer et al., 2009). Muijs (1999) proposed that grass coverings can be of high quality in terms of erosion resistance, and its strength can be even greater than some hard revetment types. Hanson and 
Temple (2001) showed that the erosion of a grass-covered dike occurred in three phases: vegetal cover failure, localized flow erosion and head cut formation, and head cut erosion and advance in the clay cover. Hoffmans et al. (2008) investigated the erodibility of clay and grass against wave overtopping, and the forces acting upon a turf-element load were modeled by the uplift force caused by bottom pressure fluctuations. Steendam et al. (2009) and van der Meer et al. (2009) used a wave simulator to study the erosive impact of wave overtopping on the grass covered dikes, and provided permissible overtopping discharge and erosion mechanics. Oumeraci et al. (2005) summarized the general theories and models of the breaching process of sea dikes, and then experimentally studied the breaching process during surge overflow and wave overtopping on a dike model with a sand core and clay surface (Geisenhainer and Kortenhaus, 2006). Failure modes for different kinds of revetments were also evaluated and some new equations were given (Doorn, 2007). Dean et al. (2010) applied experimental steady state results for acceptable overtopping to the case of intermittent wave overtopping. They predicted the failure duration of vegetative linings with good cover, average cover and poor cover using work basis.

Modern turf reinforcement mats (TRMs) have the potential to substantially increase the erosion resistance, thereby enabling their use in areas where high velocities/shear stresses are prevalent (Hewlett, et al., 1987; Northcutt and McFalls, 1998). Lancaster (1996) and Lipscomb et al. (2003) discussed the test method of TRMs. Nelson (2005) studied the permissible shear stress of TRMs, in which TRMs tested were installed over a highly erodible sandy loam soil and exposed to $1 \mathrm{~h}$ or $10 \mathrm{~h}$ surge-only overflows generating escalating levels of shear stress. It showed that the permissible shear stress for full-vegetated TRMs was as high as $900 \mathrm{~Pa}$, much higher than the design value.

\subsection{Full-scale laboratory experiments and numerical modeling of HPTRM-strengthened levee}

Pan et al. (2012) and Yuan et al. (2014a) studied the hydraulic and turbulent characteristics of full-scale HPTRM strengthened levees under combined storm surge overflow and wave overtopping using a large wave flume (LWF) equipped with a unidirectional piston wave maker. The LWF was 104 $\mathrm{m}$ long by $3.66 \mathrm{~m}$ wide by $4.57 \mathrm{~m}$ deep. The physical model was set up at full scale (1:1), as shown in Figure 2. The tested levee was about $39.8 \mathrm{~m}$ from the wave maker, with the crest elevation $3.25 \mathrm{~m}$ above the wave flume bottom, a sea-side slope of $1 \mathrm{~V}: 4.25 \mathrm{H}$ (where $\mathrm{V}$ is height and $\mathrm{H}$ is length), and a land-side slope of $1 \mathrm{~V}$ : $3 \mathrm{H}$. The model was designed according to the typical levees along the Mississippi River Gulf Outlet. A vegetated HPTRM system consisting of vegetation (warm environment Bermuda grass), HPTRM and soil, was installed on the crest and landside slope. The system was built into a steel tray put into the test section before the tests. The flow velocities on the crest and landside slope were recorded using multiple acoustic Doppler velocimeters, and the flow thickness using Acoustic range finders. Pan et al. (2012) studied one case of storm surge overflow and nine cases of combined wave and surge overtopping, and estimated the combined overtopping discharge under different overtopping conditions; while Yuan et al. (2014b) studied eleven cases of combined wave and surge overtopping, and analyzed the turbulent kinetic energy and turbulent shear stress on the crest and the landside slope.

[Figure 2 near here] 
Yuan et al. (2014b) and Li et al. (2015) studied the hydrodynamics, time-averaged bottom shear stress, turbulence and erosion of the combined overtopping flow in a 3D full-scale numerical flume, and presented a series of empirical equations to characterize representative hydraulic parameters of wave-related unsteady flow on the landside slope. Empirical correlations were sought that linked the maximum mean shear stresses, turbulent kinetic energy and erosion rate at the toe of landside slope to the significant wave height and negative freeboard, as the slope toe is where there is the maximum shear stress, turbulence and erosion.

\section{Experiment setup}

\subsection{Erosion Function Apparatus}

EFA can be used to measure the erosion function of a soil, which describes the relationship between hydraulic shear stress applied at the soil-water interface by the water flowing over the soil and erosion rate experienced by the soil (Briaud et al., 2001). The erosion function can be used to predict the scour of soil by water. In general, the samples within the depth of concern are collected at the site where erosion is being investigated, and tested in the EFA in the laboratory. The samples are taken by pushing an ASTM standard Shelby tube with a $76.2 \mathrm{~mm}$ outside diameter (ASTM, 1999a). One end of the tube full of soil is placed through a circular opening in the bottom of a pipe with a rectangular cross section of $101.6 \times 50.8 \mathrm{~mm}$. The pipe is $1.22 \mathrm{~m}$ long and has flow strengtheners at one end. The water is driven through the pipe by a pump. A valve regulates the flow and the flow rate is measured using a flow meter. A piston at the bottom end of the tube pushes the clay into the rectangular pipe at the other end. The linear erosion rate $E$ at a given velocity $V$ is:

where $\Delta h$ is the thickness of soil eroded in time $t$.

The shear stress at the bottom of the pipe is:

where $\rho$ is the density of water; $V$ is the flow velocity; and $f$ is the friction factor, which is a function of pipe Reynolds number $R$ and pipe roughness, and usually obtained from the Moody chart. The Reynolds number is $V D / v$, where $D$ is the pipe diameter, and $v$ is the kinematic viscosity of water $\left(10^{-6}\right.$ $\mathrm{m}^{2} / \mathrm{s}$ at $20^{\circ} \mathrm{C}$ ). The EFA pipe has a rectangular cross section, $D$ is the hydraulic diameter $D=4 A / P$, where $A$ is the cross-sectional flow area; and $P$ is the wetted perimeter. For a rectangular cross section pipe: 
2

where $a$ and $b$ are dimensions of the sides of the rectangle pipe, respectively.

\subsection{Clay samples}

A total of 8 samples were taken from the full scale HPTRM-strengthened levees constructed with low liquid limit clay, a commonly used clay type for the levees in Mississippi (Yuan et al., 2014a), and named A1 to B4 according to the sampling locations, as shown in Figure 2b. Samples A2, A3, A4, B3, and B4 had good grass cover, while samples A1, B1, and B2 had poor grass cover, as shown in Figure $3 \mathrm{a}$ and $\mathrm{b}$, respectively. Figure $3 \mathrm{c}$ showed the clay-only side of the Shelby tube. The clay was light brown and soft, with a plasticity index $I_{\mathrm{P}}$ of 14 and mean grain size $D_{50}$ of $0.007 \mathrm{~mm}$, and the grading curve was shown in Figure 3d. The samples were taken using a Shelby tube about $12.5 \mathrm{~cm}$ long and $7.6 \mathrm{~cm}$ in diameter, and then mailed to Texas A\&M University (TAMU). The grass sward turned yellow upon arrival at TAMU, however its influence on clay erodibility might be expected to be negligible, as shown by Hoffman et al. (2008) that the sward contributed to the strength of grass cover by covering clay aggregates during overtopping, but its contribution to actual grass strength was minor as compared to the grass roots. The samples had dried out during delivery, so they were saturated in the EFA for 10 min prior to the test.

[Figure 3 near here]

\section{Results of EFA tests}

The samples had two sides, one with grass roots and the other with clay only, thus there were supposed to be 16 tests for the 8 samples. However, the erodibility of the unprotected sides of A1, B2 and B3 was not measured as the flow velocity was set so high during the tests for the other side that there were not enough clays left. Theoretically, the erosion rate is estimated by the time required for 1 $\mathrm{mm}$ scour depth. But when the duration is too short or the visual inspection of the scour through the plexiglass window is blocked by the grass and mat, scour depth more than $1 \mathrm{~mm}$ would be used. In this study, EFA was used to analyze the erosion processes of three representative clays, including the unprotected clay, HPTRM strengthened clay with poor grass cover, and HPTRM strengthened clay with good grass cover. EFA tests of unprotected clay were stopped when the extremely high erosion rate occurred by visual inspection of the scour through the plexiglass window; while tests of protected clay with good or poor grass cover were stopped when the HPTRM was lifted up.

\subsection{Clay without protection: unprotected side of Sample A4}

Table 1 shows the EFA test results of the unprotected side of Sample A4. In step 3, the sample is eroded by $4 \mathrm{~mm}$ in $7.5 \mathrm{~min}$, and then the test is stopped because of the extremely high erosion rate. It is well known that the clay without protection is highly erodible, and it is unlikely to determine the 
time required for $1 \mathrm{~mm}$ scour depth. In this study, the erosion rate $E$ is estimated by the scour depth during a specified time. The results show that the critical shear stress for the incipient motion is much smaller than $1 \mathrm{~Pa}$, which can explain why the earthen levees without protection cannot withstand the high-speed and turbulent overtopping flow.

The erosion function is then plotted on the category chart to classify the clay (Briaud et al., 2008), where the erodibility category number for the material tested is the number for the zone in which the erosion function fits. The erosion curve of A4 is in Category II (high erodibility) as shown in Figure $4 a$.

When the erosion function is plotted in the linear coordinate system, there are two parameters defining the erodibility of cohesive soil: the critical shear stress $\tau_{c}$ and the initial slope $S_{\mathrm{i}}$ of the erosion rate vs. shear stress curve after $\tau_{c}$. Figure $4 \mathrm{~b}$ shows that the critical shear stress is $0.072 \mathrm{~N} / \mathrm{m}^{2}$ and the initial slope is $12.3 \mathrm{~mm} / \mathrm{h} / \mathrm{N} / \mathrm{m}^{2}$.

\subsection{HPTRM-strengthened clay with poor grass cover: protected side of Sample B2}

Table 1 also shows the EFA test results of the HPTRM-strengthened clay with poor grass cover. In step 4, most grass is lifted up, and the sample is eroded by $3 \mathrm{~mm}$ in $6 \mathrm{~min}$. The test is stopped to avoid excessive scour. Figure $4 \mathrm{c}$ shows that the erosion curve of B2 is in Category III (medium erodibility). Obviously, the grass roots in the top of the sample create a rough soil surface during the test, and the HPTRM with poor grass cover decrease the erodibility of the sample. Figure $4 \mathrm{~d}$ shows that the critical shear stress $\left(4.34 \mathrm{~N} / \mathrm{m}^{2}\right)$ is much higher, and the initial slope $\left(0.267 \mathrm{~mm} / \mathrm{h} / \mathrm{N} / \mathrm{m}^{2}\right)$ is much lower than the unprotected clay. The erosion rate vs. shear stress curve after $\tau_{c}$ (dotted curve) is convex, which should be associated with the lift-up of grass cover and mat.

[Figure 4 near here]

\subsection{HPTRM-strengthened clay with good grass cover: protected side of Sample A3}

Table 1 also shows the EFA test results of the HPTRM-strengthened clay with good grass cover. In step 7, 75\% of the HPTRM is lifted up and would fail very soon (Figure 5). The test is stopped at 18 min to avoid excessive scour, and an erosion of $25 \mathrm{~mm}$ is detected. Figure $4 \mathrm{e}$ shows that sample A3 is initially in Category IV (low erodibility), but then in Category III (medium erodibility) when the HPTRM reinforcement is lifted up by the flow. Also, the grass roots in the top of the sample create a rough soil surface during the test, and the HPTRM with good grass cover (more roots than poor grass cover) decreases the erodibility of the sample. Figure $4 \mathrm{f}$ shows that the critical shear stress $\left(18.5 \mathrm{~N} / \mathrm{m}^{2}\right)$ is much higher, and the initial slope $\left(0.136 \mathrm{~mm} / \mathrm{h} / \mathrm{N} / \mathrm{m}^{2}\right)$ is much lower than the poor-grass covered clays. The erosion rate vs. shear stress curve after $\tau_{\mathrm{c}}$ (dotted curve) is also convex, which should also be attributed to the lift-up of the HPTRM reinforcement.

[Figure 5 near here]

\section{Table 1}

Summary of EFA tests for Sample A4, B2 and A3. 


\begin{tabular}{ccccccc}
\hline Sample No. & Steps & $V\left(\mathrm{~m} \cdot \mathrm{s}^{-1}\right)$ & $\tau(\mathrm{Pa})$ & $h(\mathrm{~mm})$ & $t(\mathrm{~s})$ & $E\left(\mathrm{~mm} \cdot \mathrm{h}^{-1}\right)$ \\
\hline \multirow{3}{*}{$\mathrm{A} 4$} & 1 & 0.491 & 0.722 & 4 & 1800 & 8 \\
& 2 & 0.804 & 1.778 & 5 & 900 & 20 \\
& 3 & 1.093 & 3.134 & 4 & 450 & 32 \\
\hline \multirow{3}{*}{ B2 } & 1 & 0.425 & 2.709 & 0 & 2700 & 0 \\
& 2 & 0.734 & 8.081 & 1 & 3600 & 1.000 \\
& 3 & 0.977 & 14.318 & 2 & 2700 & 2.667 \\
& 4 & 1.410 & 29.822 & 3 & 360 & 30.000 \\
\hline \multirow{3}{*}{$\mathrm{A} 3$} & 1 & 0.190 & 0.614 & 0 & 2700 & 0.000 \\
& 2 & 0.499 & 4.233 & 0 & 2700 & 0.000 \\
& 3 & 0.721 & 8.837 & 0 & 2700 & 0.000 \\
& 4 & 1.000 & 17.000 & 0 & 2700 & 0.000 \\
& 5 & 1.295 & 28.300 & 1 & 2700 & 1.333 \\
& 6 & 1.685 & 47.912 & 3 & 2700 & 4.000 \\
& 7 & 2.131 & 76.632 & 25 & 1080 & 83.333 \\
\hline
\end{tabular}

1

\subsection{Results of both sides of all samples}

The erosion function curves for all samples are plotted in Figure 6. The unprotected sides of the five samples are in Category II (high erodibility), three HPTRM strengthened clays with poor grass cover are in Category III (medium erodibility) as the grass roots and mat increase surface roughness and thus decrease the erodibility, and the protected sides of the five samples with good grass cover are initially in Category IV (low erodibility) due to the protections of the grass sward, roots and mat, and then in Category III (medium erodibility) when the HPTRM is lifted up and the sample is exposed and eroded faster.

\section{[Figure 6 near here]}

The erosion rate vs. shear stress curves are plotted in the linear coordinate system for all the samples (Figure 7). It is known that there are a number of factors affecting the critical shear stress and the slope of cohesive soils. Although the samples collected in this study are of low liquid limit and well kept with least disturbance, there are still some discrepancies in these samples. The critical shear stresses are much more consistent than the slopes. The critical shear stresses are 0.059, 2.84 and 18.50 $\mathrm{N} / \mathrm{m}^{2}$ for clays with no protection, HPTRM strengthened clays with poor grass cover, and HPTRM strengthened clays with good grass cover, respectively. Thus, even a poor grass cover can be better than the unprotected clays in increasing the critical shear stress of clay, and the critical shear stress of the HPTRM strengthened clay with good grass cover is about 6 times higher than that with poor grass cover, which highlights the important contribution of full-grown grass roots to the protection of levees. The slopes vary between 5.263 and $19.231 \mathrm{~mm} / \mathrm{h} / \mathrm{N} / \mathrm{m}^{2}$ for unprotected clays, 0.178 and 0.392 $\mathrm{mm} / \mathrm{h} / \mathrm{N} / \mathrm{m}^{2}$ for HPTRM strengthened clays with poor grass cover, and 0.031 and $0.187 \mathrm{~mm} / \mathrm{h} / \mathrm{N} / \mathrm{m}^{2}$ for HPTRM-strengthened clays with good grass cover, respectively.

The lift up of HPTRM was observed in EFA test for large shear stresses. However, in our 
previous experiment on the full scale HPTRM-strengthened levee under combined storm surge overflow and wave overtopping (Yuan et al., 2014a), no lift up or swell of HPTRM was observed with much faster overtopping flow, because HPTRM was firmly interlocked with the soil as a whole. Approximate uniform erosion over time was observed in these experiments.

[Figure 7 near here]

HPTRM has been demonstrated to have a good performance in resisting flow-induced forces and preventing erosion. The erosion and failure process of HPTRM-strengthened clay under different overtopping conditions are discussed in this section. This is of special concern for the engineering application of HPTRM. At first, the mechanism of HPTRM in protecting cohesive soil is discussed.

\subsection{Turf-element model and HPTRM-element model}

Hoffmans et al. (2008) proposed a turf-element model to depict the protective mechanism of grass on levees against wave overtopping, in which the load was modeled by the uplift force caused by pressure fluctuations, whereas the strength of clay aggregate against the uplift force was characterized by the self weight of the soil, cohesion and grass strength. The maximum pressure peaks could be up to:

where $P_{\max }$ is the maximum pressure $\left(\mathrm{N} / \mathrm{m}^{2}\right) ; \tau_{0}$ is the bottom shear stress $\left(\mathrm{N} / \mathrm{m}^{2}\right)$.

Incipient motion of a grass-clay aggregate occurs when the load is larger than the strength, thus:

$P \geq\left(\rho_{s}-\rho\right) g d_{s}+c_{s}+\sigma_{g}$

where $P$ is the pressure fluctuation $\left(\mathrm{N} / \mathrm{m}^{2}\right) ; \rho_{s}$ is the soil density $\left(\mathrm{kg} / \mathrm{m}^{3}\right) ; \rho$ is the water density $\left(\mathrm{kg} / \mathrm{m}^{3}\right)$;

The critical condition of lifting the grass-clay aggregate is reached if $P=P_{\max }$ and if $\tau_{0}$ equals the critical bed shear stress $\left(\tau_{c}\right)$, thus: 
In this study, the turf-element model is modified to account for the erodibility of the HPTRM-strengthened levee. The definitions of lift force, self weight and cohesion remain unchanged, but the grass strength $\left(\sigma_{g}\right)$ is replaced with the grass-mat strength $\left(\sigma_{g, m}\right)$ :

$5 \quad \tau_{c}=\alpha_{\tau}\left(\left(\rho_{s}-\rho\right) g d_{s}+c_{s}+\sigma_{g, m}\right)$

6

Direct replacement of the grass strength by the grass-mat strength is available. Mat acts force on the grass, rather than on the soil directly. That is, Hoffman et al. (2008) is still available for HPTRM-strengthened soil, since only the value of grass force acting on the soil changes.

$d_{s}$ is the side length of the equivalent cube of a clay aggregate, which can be affected by a number of physical and chemical factors. It is therefore difficult to determine and may change from one clay to another.

The self weight and cohesion are combined into one parameter defined as soil strength $\left(\sigma_{s}\right)$ in this study. Thus:

$\tau_{c}=\alpha_{\tau}\left(\sigma_{s}+\sigma_{g, m}\right)$

Eq. (8) is the modified turf-element model for HPTRM-strengthened levee, which we call the HPTRM-element model in this study.

\subsection{Characterization of HPTRM-element model}

Eq. (8) depicts the relationship between the critical shear stress of HPTRM-strengthened clay and the properties of clay and HPTRM. The indicative values of the parameters in the HPTRM-element model could be calculated based on the EFA test results (Table 2). The results of previous experiment on the full-scale HPTRM-strengthened levees are also presented (Yuan et al., 2014b). It shows that the critical shear stress $\tau_{c}$ and grass-mat strength $\sigma_{g, m}$ of HPTRM-strengthened clay with good grass cover in EFA tests are consistent with the experimental results. So the erosion function obtained by EFA tests can be used to predict the scour rate in the field, such as scour on earthen levees against overtopping, and the same finding was also reported by Briaud et al. (2001). We can see the lower limit of HPTRM-good grass protected clay performing in the EFA tests is very close to its performance in the full scale experiment. EFA tests may be a feasible method to predict the erosion rate - shear stress curves even when the physical shear stress is larger than ones used in the EFA tests; however, the full scale experiment may be necessary to prove it, especially the linear relationship between shear stress and erosion rate should exist. We will discuss this linear relationship in the later section.

The soil strength is small and negligible as compared with the grass-mat strength. The growth conditions of grass, especially the roots, can have a considerable effect on the performance of HPTRM. The strength of HPTRM with good grass cover is six times greater than that with poor grass cover. 
Table 2

Indicative values for bare clay and clay with protections.

\begin{tabular}{cccccc}
\hline Tests & Clay type & $\begin{array}{c}\tau_{c} \\
\left(\mathrm{~N} / \mathrm{m}^{2}\right)\end{array}$ & $\begin{array}{c}\sigma_{s} \\
\left(\mathrm{~N} / \mathrm{m}^{2}\right)\end{array}$ & $\begin{array}{c}\sigma_{g, m} \\
\left(\mathrm{~N} / \mathrm{m}^{2}\right)\end{array}$ & $\begin{array}{c}K_{d} \\
\left(\mathrm{~mm} / \mathrm{hr} / \mathrm{N} / \mathrm{m}^{2}\right)\end{array}$ \\
\hline \multirow{2}{*}{ EFA } & Unprotected & 0.059 & 1.05 & 0 & $5.263-19.231$ \\
& Poor grass & 2.84 & 1.05 & 50 & $0.178-0.392$ \\
& Good grass & 18.50 & 1.05 & 329 & $0.031-0.187$ \\
\hline \multirow{2}{*}{ Full scale } & Good grass & 17.00 & 1.05 & 303 & 0.028 \\
\hline
\end{tabular}

Note: $\tau_{c}$ is the intercept on the $\mathrm{x}$ axis in Figure 7(b), (d) and (f). $\sigma_{s}$ is assumed to be identical for all clays with protections. $\sigma_{g, m}$ is calculated by Eq. (8). $K_{d}$ represents the slopes of fitted lines in Figure 7(b), (d) and (f). The parameters of "Full scale" are decided by the full-scale HPTRM-strengthened levees (Yuan et al., 2014b).

\subsection{Failure process of HPTRM-strengthened levee against steady overtopping}

The excess stress equation, a commonly used erosion model, is used to depict the erosion process and failure of clay with or without protection:

where $E$ is the erosion rate $(\mathrm{mm} / \mathrm{hr}) ; h$ is the clay thickness $(\mathrm{mm}) ; t$ is the time (hour); $K_{d}$ is the erodibility coefficient $\left(\mathrm{mm} / \mathrm{hr} / \mathrm{N} / \mathrm{m}^{2}\right)$; and $b$ is an exponent.

The results of EFA tests are used as inputs of Eq.(9). From Figure 7, $b$ approximates 1 for both the unprotected and HPTRM strengthened clay and $K_{d}$ is the slope of erosion function curve. The values of $K_{d}$ in EFA tests and the full-scale experiment are listed in Table $2(b=1)$, and it shows that $K_{d}$ in the experimental results is close to the lower limit of the EFA test results of HPTRM-strengthened clay. The erodibility coefficient $K_{d}$ that was obtained in small shear stress is used to predict large shear stress in levee overtopping in this study. This approach is based on the hypothesis that there is a linear relationship between erosion rate and shear stress existing for much larger shear stress than EFA tests. The results of EFA tests show that the erosion rate increases in a relationship close to linear in the range of relative small shear stress, and increases sharply after a certain threshold of shear stress, as in Figure 4. Since the HPTRM on the EFA samples could not be anchored as same as in the field, the mat is relatively easy to be lifted up. Under the assumption of that HPTRM is strictly fastened, a linear relationship between erosion rate and shear stress exists for much larger shear stress is hypothesized in this study. The hypothesis will be discussed in the later section.

For the steady overtopping, the bottom shear stress on the levee slope is assumed to be constant over time. Integrate Eq. (9), thus: 
3

where $\Delta h\left(t_{0}\right)$ is the scour depth during $t_{0}(\mathrm{~mm}) ; h(0)$ and $h\left(t_{0}\right)$ are the clay thickness at $t=0$ and $t=t_{0}$, respectively.

In this study, the failure of HPTRM-strengthened clay is defined as the removal of an average of $100 \mathrm{~mm}$ thick soils from beneath the mats, which is the average root depth of grass in the full scale experiment and EFA tests. Then the relationships between the bottom shear stress and the duration for all samples obtained by Eq. (10) are plotted in Figure 8, where the lower limits of $K_{d}$ in Table 2 are used.

Note that, for unprotected clay, the shear stress in overtopping, which is much larger than the shear stress in EFA tests, will cause unpredicted erosion, and linear relationship in case of small shear stress $(<7 \mathrm{~Pa})$ in EFA tests will no longer exist in overtopping condition. Because clay may be eroded lump by lump and vertical headcut develops. So the dotted curve is used in Figure 8, which means the erosion is unpredictable. It may be the same situation for HPTRM protected clay with bad grass. However, HPTRM protected clay with good grass can endure strong overtopping and high shear stress, and the linear relationship between shear stress and erosion rate still exists.

[Figure 8 near here]

\subsection{Failure process of HPTRM-strengthened levee against combined overtopping}

It is known that on the landside slope, the sward contributes, albeit modestly, to the strength of the grass cover by covering the clay aggregates during overtopping, and near the surface, the strength is dominated by the root and mat reinforcement. The failure of HPTRM-strengthened levees during overtopping occurs in several stages. In the initial stage, elementary dispersed, loosened aggregates separate, and those aggregates torn out of the surface are washed away by the flow. This process leads to many small shallow scours (Figure 9) on the surface that can be gradually enlarged and deepened at an approximately uniform speed, but no vertical headcut or pulling out of grass occurs due to the protection of HPTRM. When the scour depth is up to about the length of grass roots, the roots are completely exposed and thus can no longer provide protection against flooding, and HPTRM fails. After that, the failure process may be the same as that for the earthen levees without protection, and vertical headcuts lead to the final breach of the levees.

[Figure 9 near here]

The bottom shear stress is assumed to be constant over time in Eq. (10), thus Eq. (10) is not applicable for the case of combined wave overtopping and storm surge overflow where the bottom shear stress on the land-side slope changes over time due to the random waves. The erodibility coefficient $K_{d}$ is assumed to be constant over time and $b=1$. Integrate Eq. (9), thus: 
2

3

4 5

$8 \quad \bar{\tau}_{0 i}=\int_{\Delta t_{i}} \tau_{0}(t) \mathrm{d} t / \Delta t_{i}$

$10 \quad \bar{\tau}_{02 i}=\int_{\Delta t_{2 i}} \tau_{0}(t) \mathrm{d} t / \Delta t_{2 i}$

11

$$
\overline{\tau_{0}}=\int_{\Delta T} \tau_{0}(t) \mathrm{d} t / \Delta T
$$

$14 \quad \overline{\tau_{02}}=\int_{\Delta T_{2}} \tau_{0}(t) \mathrm{d} t / \Delta T_{2}$

15

16

17

$$
\Delta h(\Delta T)=K_{d} \sum_{i=1}^{n}\left(\overline{\tau_{0 i}}-\tau_{c}\right) \Delta t_{i}-K_{d}\left[\sum_{i=1}^{n}\left(\overline{\tau_{0 i}}-\tau_{c}\right) \Delta t_{i}-\sum_{i=1}^{n}\left(\int_{\Delta t_{i i}}\left(\tau_{0}(t)-\tau_{c}\right) \mathrm{d} t\right)\right]
$$




$$
1 \quad \Delta h(\Delta T)=K_{d} \sum_{i=1}^{n}\left[\left(\overline{\tau_{0 i}}-\tau_{c}\right) \Delta t_{i}+\left(\tau_{c}-\overline{\tau_{02 i}}\right) \Delta t_{2 i}\right]
$$

2

$25 \frac{\overline{\tau_{0}}}{\rho g\left(-R_{c}\right)}=\alpha\left(\frac{-R_{c}}{H_{m 0}}\right)^{-0.282} \quad$ with $\quad \alpha=0.1052$

$$
\bar{\tau}_{0 i}>>\tau_{c}>\bar{\tau}_{02 i}
$$

Thus, Eq. (12) can be approximated as:

$$
\Delta h(\Delta T) \approx K_{d} \sum_{i=1}^{n}\left(\overline{\tau_{0 i}}-\tau_{c}\right) \Delta t_{i}=K_{d}\left(\overline{\tau_{0}}-\tau_{c}\right) \Delta T
$$
why we use Eq. (19) to replace Eq. (11). and $\Delta t_{i}>>\Delta t_{2 i}$. $4.25 \mathrm{H}$, and the land-side slope of $1 \mathrm{~V}: 3 \mathrm{H}$.

\section{It is known that $\overline{\tau_{0 i}}>\tau_{c}>\bar{\tau}_{02 i}$ and $\Delta t_{i}>\Delta t_{2 i}$. It is assumed that:}

When Eq. (18) is valid, Eq. (19) can well predict the scour depth of the landside slope of HPTRM strengthened levees against the combined surge overflow and wave overtopping. It is difficult to measure $\tau_{0}(t)$ on the landside slope, especially at the toe where there is the maximum shear stress, turbulence and erosion. More often, the time-averaged bottom shear stress $\overline{\tau_{0}}$ is available, that is

Yuan et al. (2014b) used a 3D numerical model to simulate the HPTRM-strengthened levees against the combined overtopping with JONSWAP random spectrum. About 100 waves with different heights and freeboards were modeled in 700 seconds. An example of time series of the bottom shear stress at the toe of land-side slope is plotted in Figure 10. Obviously, Eq. (18) is satisfied in this case,

\section{[Figure 10 near here]}

Yuan et al. (2014b) presented an empirical equation for the time-averaged bottom shear stress at the toe of landside slope of a HPTRM-strengthened levee against the combined overtopping:

where $\rho$ is the water density $\left(\mathrm{kg} / \mathrm{m}^{3}\right), g$ is the gravity acceleration $\left(\mathrm{m} / \mathrm{s}^{2}\right), R_{c}$ is the crest freeboard $(\mathrm{m})$, and $H_{\mathrm{m} 0}$ is the energy-based significant wave height $(\mathrm{m})$. Note that the application of Eq. (20) is limited to the range of tested parameters used by Yuan et al. (2014b), like the sea-side slope of $1 \mathrm{~V}$ :

Combining Eqs. (19) and (20) yields the erosion process at the toe of the landside slope of 
4

$$
\Delta T_{0}=\frac{\Delta h\left(\Delta T_{0}\right)}{K_{d, H}\left[\operatorname{\alpha \rho g}\left(-R_{c}\right)\left(\frac{-R_{c}}{H_{m 0}}\right)^{-0.282}-\tau_{c, H}\right]}
$$

where $K_{d, H}$ is the erodibility coefficients, and $\tau_{c, H}$ is the critical shear stress of HPTRM-strengthened clay, $\Delta T_{0}$ is the duration before HPTRM failure could be calculated by the following equation:

where $\Delta h\left(\Delta T_{0}\right)$ is the averaged length of grass roots, which is $100 \mathrm{~mm}$ in this study.

Figure 11 gives an example of the time history of scour depth at the toe of landside slope, where $R_{c}=-0.3 \mathrm{~m}, H_{m 0}=0.3 \mathrm{~m}, K_{d, H}=0.031 \mathrm{~mm} / \mathrm{hr} / \mathrm{N} / \mathrm{m}^{2}, \tau_{c, H}=18.5 \mathrm{~N} / \mathrm{m}^{2}$. It takes about 10.8 hours for HPTRM to fail at the toe of land-side slop with $\Delta h\left(\Delta T_{0}\right)=100 \mathrm{~mm}$. After that, much more severe scour occurs, which may result in vertical headcut. Figure 12 depicts the relationship between the overtopping conditions and the duration by using Eq. (22) with $\Delta h\left(\Delta T_{0}\right)=100 \mathrm{~mm}$. The duration could be determined by the freeboard and significant wave height specified by Eq. (21) or Figure 12, and vice verse.

\section{[Figure 11 near here]}

[Figure 12 near here]

The time-averaged shear stress and velocity along the levee are also given by Yuan et al. (2014b), which could be used to predict the erosion profile along the levee. Profiles of time-average shear stress and velocity distributions along the top and slope of levee against combined overtopping with different random waves are given in Figure 13(a) and (b). Predicted erosion thickness along the levee after 6 hours overtopping is calculated by Eq.(19) as shown in Figure 13(c).

\section{[Figure 13 near here]}

\subsection{Discussion on validation of the proposed analytic equation}

Validation of the proposed analytic update (Eq. 19) will be discussed. Eq. (19) exists only if $\bar{\tau}_{0}>\tau_{c}$, or:

31

$32 \quad \sum_{i=1}^{n}\left(\bar{\tau}_{0 i}-\tau_{c}\right) \Delta t_{i}>>\sum_{i=1}^{n}\left(\tau_{c}-\bar{\tau}_{02 i}\right) \Delta t_{2 i}$ 
$3 \quad\left(\overline{\tau_{0}}-\tau_{c}\right) \Delta T>\left(\tau_{c}-\bar{\tau}_{02}\right) \Delta T_{2}$

$6 \quad \frac{\overline{\tau_{0}}-\tau_{c}}{\tau_{c}}>>1$

That is:

Figure 14 depicts the $\left(\overline{\tau_{0}}-\tau_{c}\right) / \tau_{c}$ at the landside slope of HPTRM-strengthened levees under

9 different combined overtopping conditions. It shows that $\left(\overline{\tau_{0}}-\tau_{c}\right) / \tau_{c}>10$ and Eq. (19) can exist

10 under almost all conditions, except for weak overtopping (e.g., $\left.-R_{\mathrm{c}}<0.1 \mathrm{~m}\right)$. Fortunately, weak

$\Delta T>\Delta T_{2}$. A sufficient but not necessary condition is: overtopping with small freeboard will not cause significant damage to levees with strengthening systems.

\section{[Figure 14 near here]}

Yuan et al. (2014b) established a 3D numerical model of full scale levee against combined overtopping with freeboard $R_{\mathrm{c}}$ ranging from $-0.3 \mathrm{~m}$ to $-0.9 \mathrm{~m}$ and random waves with a JONSWAP spectrum and energy based significant wave height $H_{\mathrm{m} 0}$ up to $4.66 \mathrm{~m}$. The erosion rate was predicted by this model. The test results were used to compare with the estimates given by Eq.(19) with the shear stress $\overline{\tau_{0}}$ estimated by Eq. (20) as shown Figure 15. A small overestimate $(+20 \%)$ was observed, which could be caused by the different conditions of mat and grass in EFA tests and full scale tests. Thus it is important to reduce the difference in samples and give more precise estimates.

\section{[Figure 15 near here]}

\subsection{Discussion on linear relationship for HPTRM-strengthened clay}

A linear relationship between erosion rate and shear stress is hypothesized to exist for much larger shear stress than EFA tests. The linear relationship can be used to estimate help to the erosion in overtopping cases with EFA test results. Compared to full-scale overtopping tests, the EFA tests have two limitations: 1) EFA can not develop enough bottom shear stress as large as that on the land-side slope during the combined wave and surge overtopping. 2) The HPTRM on the samples in EFA tests could not be anchored as same as in the field, the mat is relatively easy to be lifted up. When the mat was lifted up, erosion rate could increase sharply as dotted curves shown in Figure 4. Two series of tests have conducted in this study to verify this hypothesis: EFA-similar tests and full-scale overtopping tests.

A similar test has been designed to conduct the EFA test at the Hohai University. The experimental setup is shown in Figure 16. The experimental setup can develop a water head up to $2 \mathrm{~m}$ and provide shear stress up to $165 \mathrm{~Pa}$ at the test area. The grass and clay used in the tests are same as 
EFA tests. Unlike EFA tests, the clay samples here were large enough $(61 \mathrm{~cm} \times 20 \mathrm{~cm} \times 20 \mathrm{~cm})$ for mat strictly fastened with U-shaped pin as in the field, and the edges of mat were fastened to the four sides of the sample. Six cases were conducted with three HPTRM-strengthened clay samples under two different shear stresses (132 Pa and $165 \mathrm{~Pa})$.

The experimental setup of full-scale overtopping tests is shown in Figure 2a. The steady storm surge overflow over the full-scale HPTRM protected levee was run with the surge height $R_{c}=30 \mathrm{~cm}$. After continuous overflow for one hour, erosion thicknesses of clay along the land-side slope were measured. The shear stresses along the slope were decided by the numerical modeling (Yuan et al., 2014b). The largest shear stress went to about $220 \mathrm{~Pa}$.

Figure 17 shows the results of EFA-similar tests and full-scale overtopping tests, together with EFA results. There was no lift-up of mat observed during the EFA-similar tests. A good linear relationship between erosion rate and shear stress is shown when the shear stress is large (165-220 Pa). The erosion coefficient $K_{d}$ was calculated in the range of $(0.032,0.042 \mathrm{~Pa})$ with the EFA-similar tests. The lower limit $(0.032 \mathrm{~Pa})$ is very close to the low limit erosion coefficient of EFA tests $(0.031 \mathrm{~Pa}$; Sample B3), and also close to that of full-scale overtopping tests (0.028 Pa). Samples A2 and A3 show a larger erosion coefficient possibly due to the relative worse grass grow-conditions compared with Sample B3. It is suggested that HPTRM-strengthened clay samples with better growth-condition grass should be selected, and more tests with mat strictly fastened in EFA tests should be conducted to achieve better results. The low limit of the range of erosion coefficient should be used for erosion estimates of levee under combined overtopping.

\section{Conclusion}

Levees are critical components of coastal structures used to protect people and infrastructure close behind them. However, it is possible for water to overtop the levees due to storm surge and waves, resulting in catastrophic damages. Thus, it seems to be particularly important to prevent erosion and breach of levees, which would allow for more time for the evacuation of people and property and therefore minimize losses. HPTRM has emerged as one of the most effective and flexible strengthening systems to prevent earthen levees from erosion and damage by high-speed and turbulent overtopped flows.

EFA was used to investigate the protection ability and failure process of HPTRM strengthened clay. Eight standard undisturbed samples were taken from a HPTRM-strengthened levee slope. Three of them had poor grass cover, and the remaining samples had good grass cover. Each sample had two sides, one with grass roots and the other with clay only. EFA tests were performed to compare the erodibility of the clay with no protection, poor grass cover, and good grass cover.

The erodibilities were classified in accordance with the categories proposed in a previous study. The erosion rate versus shear stress curve for clay without HPTRM protection is in Category II (high erodibility), where the critical shear stress is much smaller than $1 \mathrm{~Pa}$ and the initial slope is high, indicating that the levees without protection cannot withstand the overtopping flow. The curve for clay with poor grass cover is in Category III (medium erodibility), thus even a poor grass cover can be better than the unprotected clay in protecting the levees. As expected, good grass cover could reduce 
the erodibility of the sample, as the curve is initially in Category IV (low erodibility), and then in Category III (medium erodibility) when clay is exposed after the lift-up of the HPTRM.

A modified turf-element model is developed in this study, in which the load is modeled by the uplift force caused by pressure fluctuations, whereas the strength of clay aggregate against the uplift force is characterized by the self weight and cohesion of the soil and HPTRM root and mat forces. These forces are well estimated by EFA test results. It is found that the growth conditions of grass, especially the roots, can have a considerable effect on the performance of HPTRM. The strength of HPTRM with good grass cover is six times greater than that with poor grass cover.

For HPTRM-strengthened levees against combined wave and surge overtopping, the bottom shear stress and pressure fluctuations are random and change over time. The overtopping flows loose aggregates and tear them out of the slope surface. Shallow scours on the surface appear and gradually enlarged and deepened. When excessive erosion occurs, grass roots are completely exposed and can no longer provide protection against overtopping flow. After that the failure process may be the same as that for earthen levees without any protection, and headcut leads to the breach of the levees. A failure model is then developed based on the excess stress equation, and the durations of HPTRM-strengthened levees against the overtopping with different wave heights and freeboards are presented. This failure model is available under almost all conditions, except for weak overtopping with small freeboard, which will not cause significant damage to levees with strengthening systems fortunately.

In this paper, the EFA tests results were used to decide the relationship between the shear stress and erosion rate, even when the physical shear stress in the combined overtopping is more random and larger than ones used in the EFA tests. Samples with good growth-condition grass should be chosen for EFA tests, and mat needs to be strictly fastened. More EFA tests may bring about more accurate predictions, and the lower limit of erosion rate may be appropriate for erosion prediction. The fact that the mat was not strictly fastened in EFA tests this study made test data random for large shear stresses when the mat was lifted up, and resulted that a scale problem might exists between the laboratory tests and field conditions. Although the linear relationship for HPTRM-strengthened clay was discussed with the EFA-similar tests and full-scale experiment, the additional EFA testing with HPTRM strictly fastened is definitely the best way to give strong supports to our conclusions, and it will be the concern in our further research.

\section{Acknowledgements}

This research was funded by China National Funds for Distinguished Young Scientists (51125034), National Science Foundation of China (51239003, 51279046, 51109065), and National Basic

36 Research Program of China (2011CB403303). It was also funded by the Department of Homeland 37 Security-sponsored Southeast Region Research Initiative (SERRI) at the Department of Energy's Oak 38 Ridge National Laboratory. The opinions and conclusions described in this paper are solely those of 39 the authors and do not necessarily reflect the opinions or policies of the sponsors. Thanks are also 40 extended to Huiming Zhang of Hohai University, and Yongtao Li of Water Resources Department of 41 Jiangsu Province, for their support during the paper modification. The authors appreciate the 
comments and suggestions by three anonymous Reviewers which contributed to the quality of this

2 final paper.

3

ASCE Hurricane Katrina External Review Panel. 2007. The New Orleans hurricane protection system:

\section{References}

What went wrong and why? American Society of Civil Engineers, Reston, Virginia: 92 p.

ASTM 1999. Standard practice for thin-walled tube geotechnical sampling of soils. ASTM-D1587, West Conshohochen, Pa.

Bosman G. 2007. Velocity and flow depth variations during wave overtopping. Master Thesis, Delft University of Technology, The Netherlands.

Briaud JL, Chen HC, Govindasamy AV, and Storesund R. 2008. Levee erosion by overtopping in New Orleans during the Katrina Hurricane. Journal of Geotechnical and Geoenvironmental Engineering 134(5): 618-632.

Briaud JL, Ting FCK, Chen HC, Cao Y, Han SW, Kwak KW. 2001. Erosion function apparatus for scour rate predictions. J. Geotech. Geoenviron. Eng. 127(2): 105-113.

Chen YH, Anderson BA. 1987. Development of a methodology for estimating embankment damage due to flood overtopping. Turner-Fairbank Highway Research Center Report No. FHWA/RD-86/126. Washington, DC: Federal Highway Administration.

Dean RG, Rosati JD, Walton TL, Eage BL. 2010. Erosional equivalences of levees: Steady and intermittent wave overtopping. Ocean Engineering. 37(1): 104-113.

Doorn N. 2007. Understanding and predicting failure modes - Activity 4.1: Failure modes for revetments, FLOODsite Project Report.

Geisenhainer P, and Kortenhaus A. 2006. Hydraulic model tests on breaching with and without waves: description of experiments performed at LWI, FLOODsite Project Report. Report Number T06-06-02.

Goodrum R. 2011. A Comparison of sustainability for three levee armoring alternatives. Optimizing Sustainability Using Geosynthetics, the 24th Annual GRI conference Proceedings, edited by Koerner, G.R., Koerner, R. M., Ashley, M. V., Hsuan, G. Y., and Koerner J., R., Dallas, Texas, March 16: 40-47.

Hahn W, Hanson G, Cook K. 2000. Breach morphology observations of embankment overtopping tests. Water Resources: 1- 10.

Hanson GJ, Temple DM. 2001. Performance of bear earth and vegetated steep channels under long duration flows. ASAE Meeting Presentation.

Hewlett HM, Boorman LA, Bramley ME. 1987. Guide to the design of reinforced grass waterways. CIRIA Report 116, London, U.K.

Hoffmans G, Akkerman, GJ, Verheij HJ, Van Hoven A, Van der Meer JW. 2008. The erodibility of grassed inner dike slopes against wave overtopping. In: Proceedings of the 31st International Conference of Coastal Engineering, Hamburg, Germany: 2944-2956.

Hughes SA. 2008. Levee overtopping design guidance: What we know and what we need. Proceedings of the Solutions to Coastal Disasters Congress 2008. 
Hughes SA, Nadal NC. 2009. Laboratory study of combined wave overtopping and storm surge overflow of a levee. Coastal Engineering 56(3): 244-259

Kelley D, Thompson R. 2008. Comprehensive hurricane levee design: Development of the controlled overtopping levee design logic. SAME Technology Transfer Conference and Lower Mississippi Regional Conference, March 17-19, Vicksburg, MS.

Muijs JA. 1999. Grass cover as a dike revetment. Translation of TAW-brochure "Grasmat als Dijkbekleding”, Rijkswaterstaat, Delft.

Lancaster T. 1996. A three phase turf reinforcement system: A new method for developing geosynthetically reinforced vegetated linings for permanent channel protection. International Erosion Control Association, Proceedings of Conference 27, 345-354.

Li L, Yuan S, Amini F, and Tang H. 2015. Numerical study of combined wave overtopping and storm surge overflow of HPTRM strengthened levee. Ocean Engineering 97:1-11.

Lipscomb CM, Theisen M, Thornton CI, Abt SR. 2003. Performance testing of vegetated systems and engineered vegetated systems. Proceedings of the International Erosion Control Association Conference Number 34, January.

Nelson RJ. 2005. Research quantifies performance of TRM reinforced vegetation. Proceedings of the Sessions of the Geo-Frontiers 2005 Congress, Austin, Texas, USA

Northcutt P, McFalls J. 1998. Performance testing of erosion control products - What have we learned after five complete evaluation cycles. International Erosion Control Association, Proceedings of Conference 29: 199-218.

Oumeraci H, D'Eliso C, Kortenhaus A. 2005. Breaching of coastal dikes: State of the art and study plan overview, FLOOD site Project Report. Progress report Nr. 1, LWI report Nr. 910.

Pan Y, Li L, Amini F, Kuang C. 2012. Full scale HPTRM strengthened levee testing under combined wave and surge overtopping conditions: Overtopping hydraulics, shear stress and erosion analysis. Journal of Coastal Research 29(1): 182-200.

Powledge GR, Ralston DC, Miller P, Chen YH, Clopper PE, Temple DM. 1989a. Mechanics of overflow erosion on embankments. I: Research activities. Journal of Hydraulic Engineering 115(8): 1040-1055.

Powledge GR, Ralston DC, Miller P, Chen YH, Clopper PE, Temple DM. 1989b. Mechanics of overflow erosion on embankments. II: Hydraulic and design considerations. Journal of Hydraulic Engineering 115(8): 1056-1075.

Ralston DC. 1987. Mechanics of embankment erosion during overflow. Hydraulic Engineering, Proceedings of the 1987 ASCE National Conference on Hydraulic Engineering, Williamsburg, Virginia, August 3-7: 733-738.

Sills GL, Vroman ND, Wahl RE, Schwanz NT. 2008. Overview of New Orleans levee failures: Lessons learned and their impact on national levee design and assessment. Journal of Geotechnical and Geoenvironmental Engineering 134(5): 556-565.

Singh VP. 1996. Dam breach modeling technology. Kluwer Academic Publisher.

Steendam GJ, Vries WD, van der Meer JW, Hoven AV, Raat GD, Frissel JY. 2009. Influence of management and maintenance on erosive impact of wave overtopping on grass covered slopes of dikes; Tests. Flood Risk Management: Research and Practice. Taylor \& Francis Group, London. 
1 Temple DM. 1989. Mechanics of an earth spillway failure. Transactions of the ASABE 32(6): 2 2015-2021.

3 Temple DM, Robinson KM, Ahring RM, Davis AG. 1987. Stability design of grass-lined open

4 channels. Agriculture Handbook Number 667, U.S. Department of Agriculture, Agricultural 5 Research Service.

6 van der Meer JW, Schrijver R, Hardeman B, van Hoven A, Verheij H, Steendam GJ. 2009. Guidance 7 on erosion resistance of inner slopes of dikes from three years of testing with the Wave 8 Overtopping Simulator. Proc. ICE, Coasts, Marine Structures and Breakwaters 2009, Edinburgh, 9 UK.

Visser PJ. 1998. Breach growth in sand-dikes. Communications on Hydraulic and Geotechnical Eng., Report No. 98-1, Delft University of Technology, The Netherlands.

Yuan S, Li L, Amini F, Tang H. 2014a. Turbulence measurement of combined wave and surge overtopping over a full-scale HPTRM-strengthened levee. J. Waterway, Port, Coastal, Ocean Eng., 140(4): 04014014.

Yuan S, Li L, Amini F, Tang H. 2014b. Numerical study of turbulence and erosion of an HPTRM-strengthened levee under combined storm surge overflow and wave overtopping. Journal of Coastal Research, 30(1): 142-157.

Yuan S, Li L, Amini F, Tang H. 2014c. Sensitivity of combined turbulent wave overtopping and storm surge overflow response to variations in levee geometry. Journal of Coastal Research, 31(3): $702-713$.

Zhu Y. 2006. Breach growth in clay-dikes. Ph.D. thesis, Technical University Delft, Civil Engineering Department, Delft, The Netherlands, $231 \mathrm{p}$. 


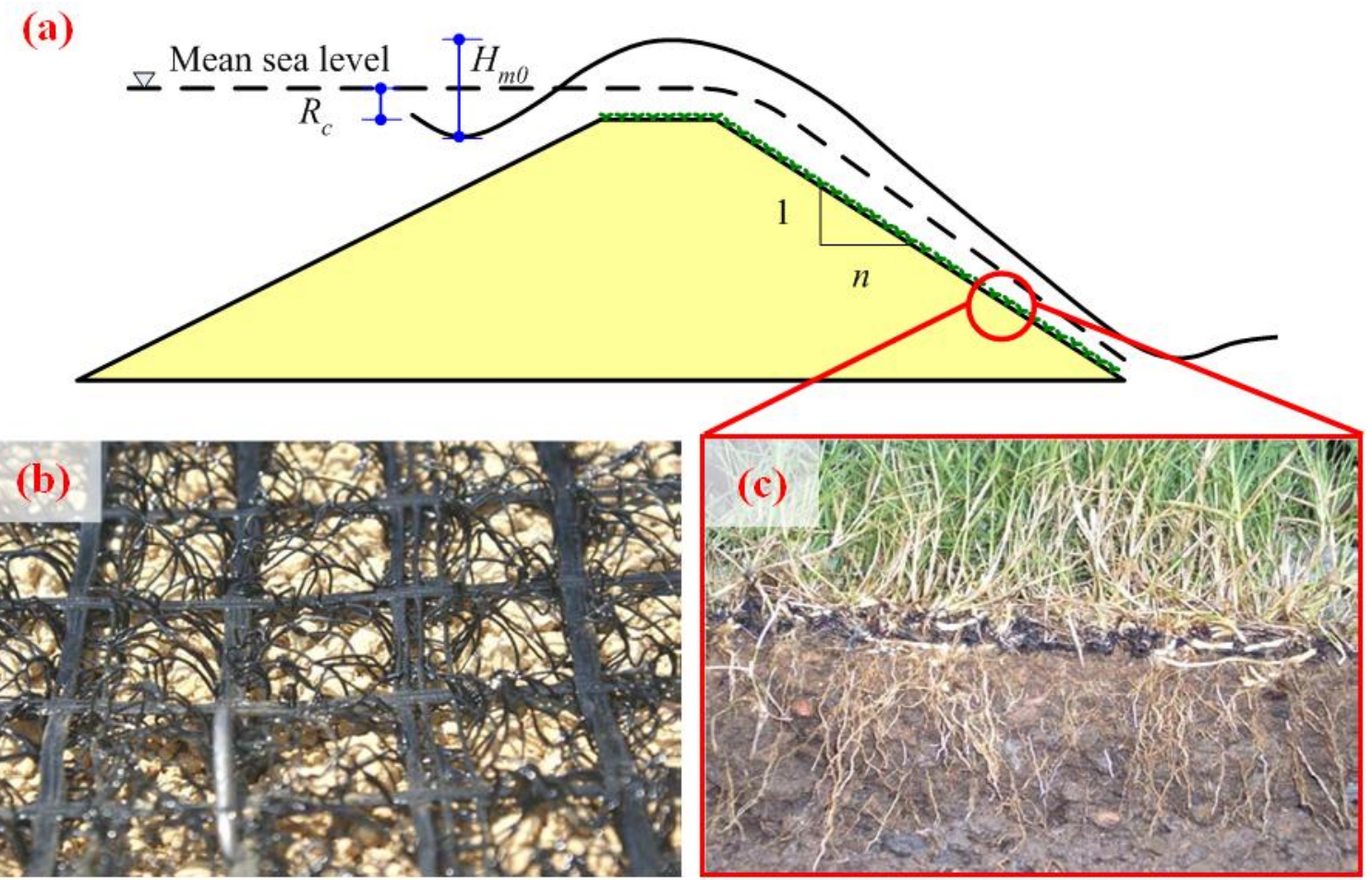

Figure 1. Illustrations of HPTRM strengthening system: (a) combined surge and wave overtopping scenario for earthen levees strengthened with HPTRM on crest and land-side slope $\left(R_{c}<0\right)$ (Freeboard $R_{c}$ is defined as the difference between the mean sea level and the elevation of the levee crest, $n$ is land-side slope), (b) details of the three-dimensional structure of HPTRM mat. U-Shaped pin is used to fix the HPTRM mat on clay, and (c) vegetated HPTRM system. 
(a)
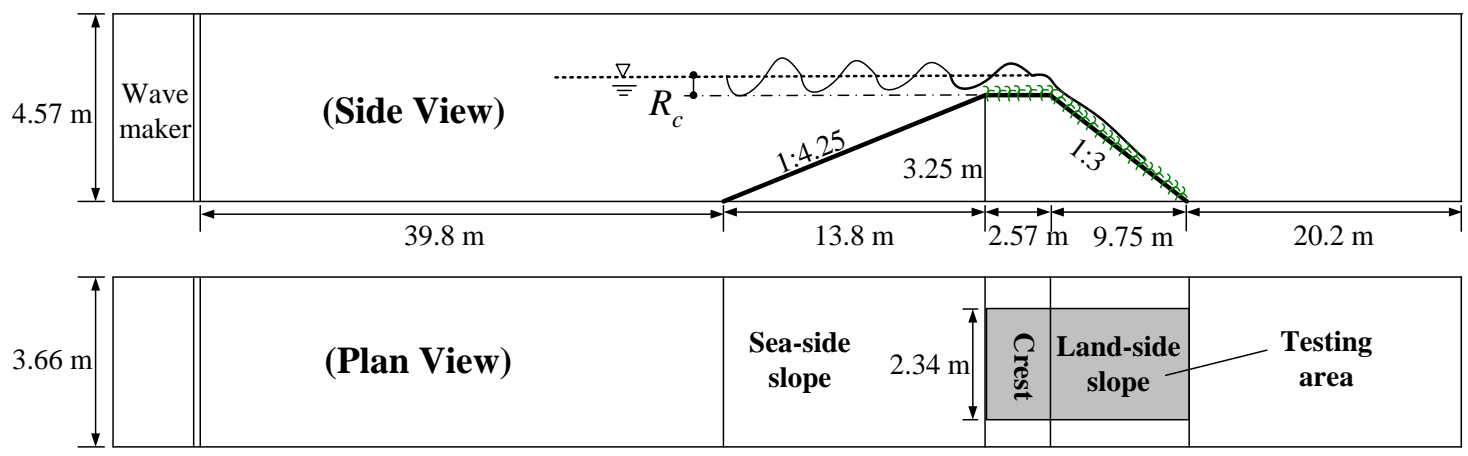

(b)
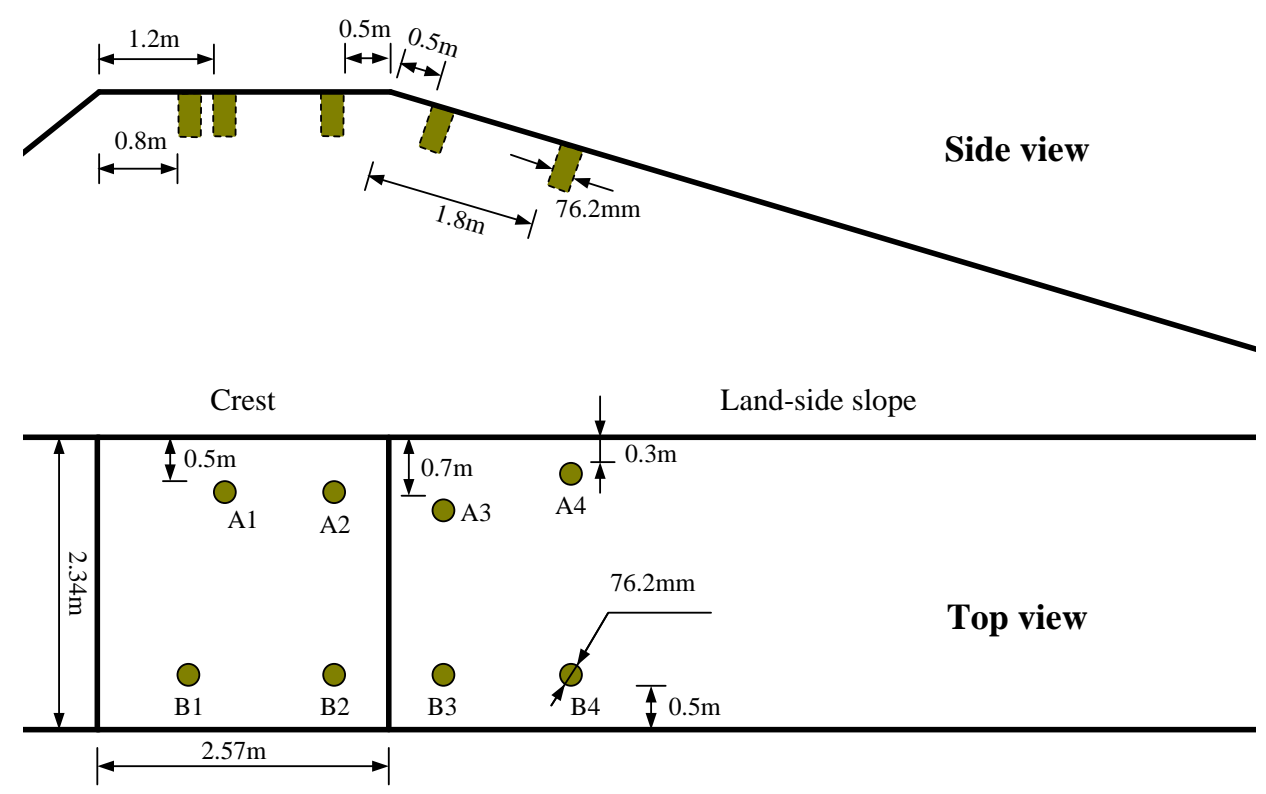

Figure 2. Schematic diagrams of LWF and full scale HPTRM-strengthened levee against the combined wave and surge overtopping (a), and sampling locations on the crest and landside slope (b). 

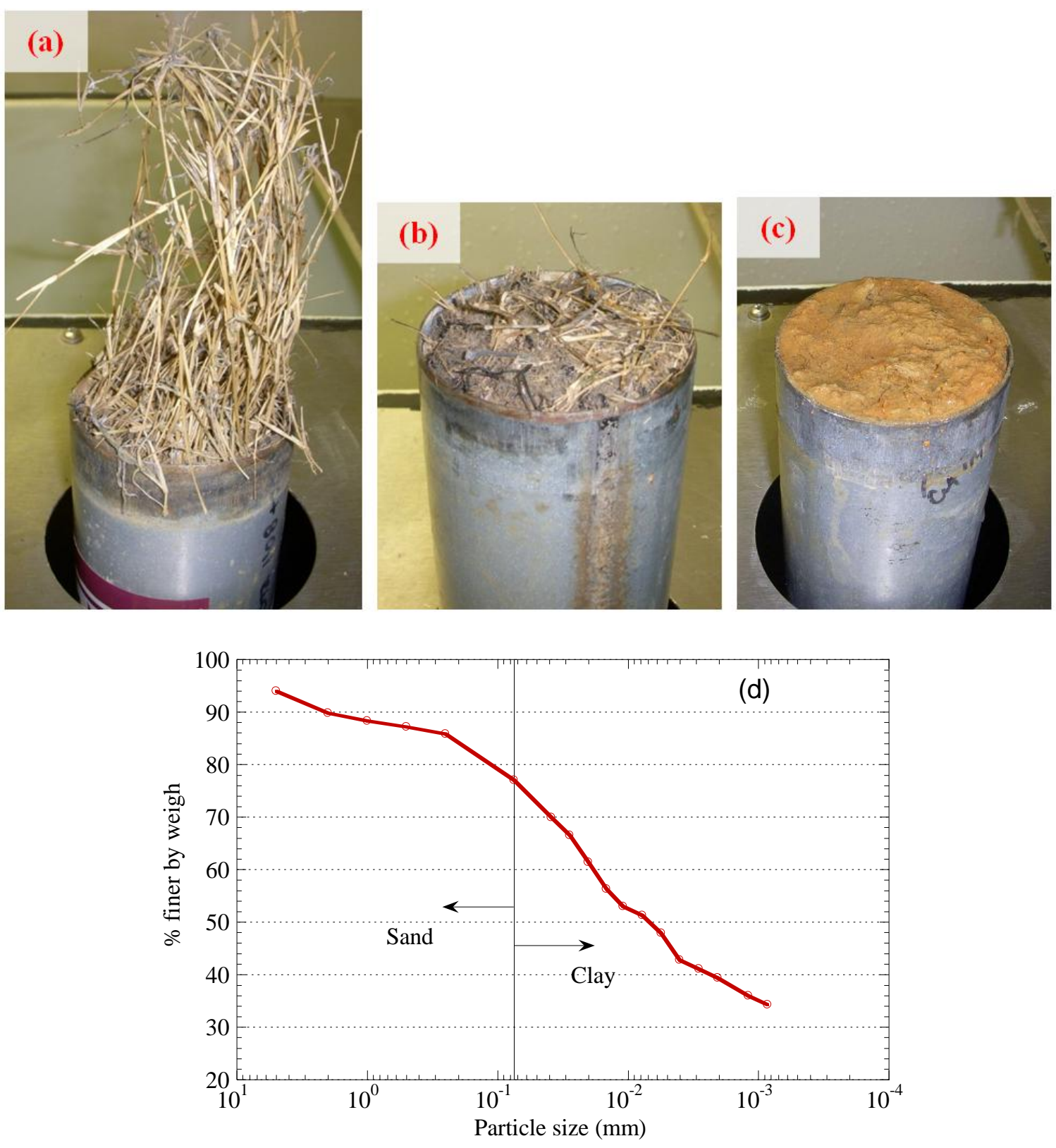

Figure 3. Examples of clays with good grass cover (Sample B3, (a)), poor grass cover (Sample A1, (b)), and without protection (Sample A4, (c)); (d) Grading curve of the sample soil. 
(a)

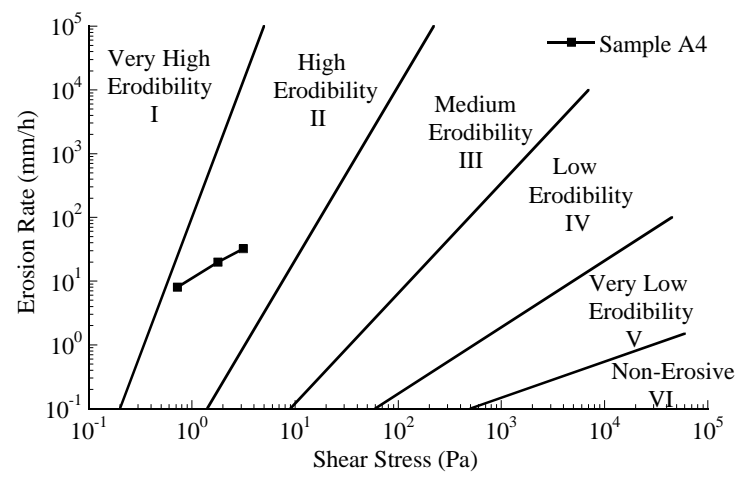

(c)

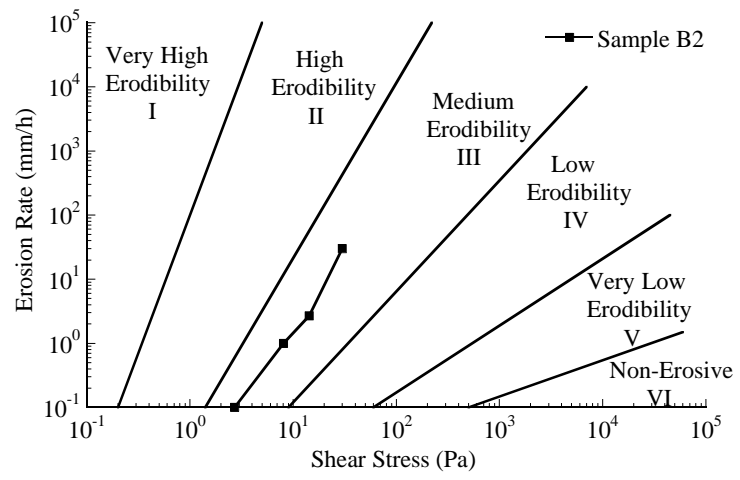

(e)

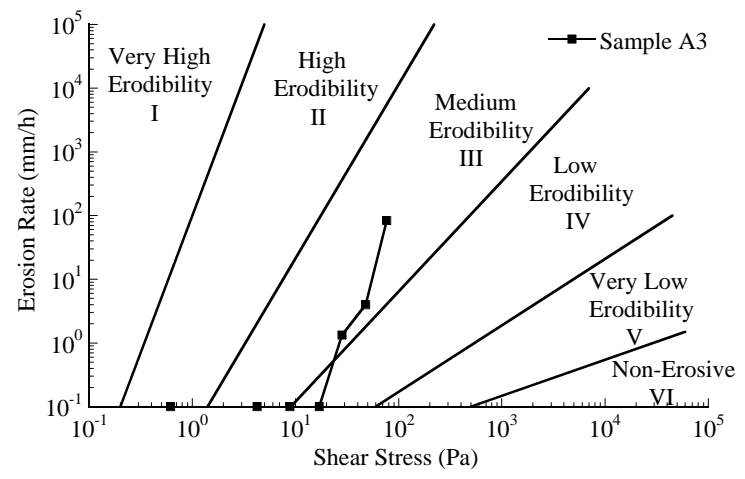

(b)

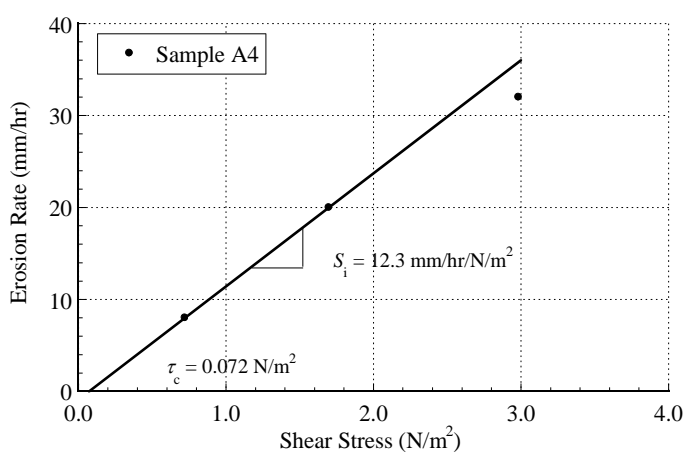

(d)

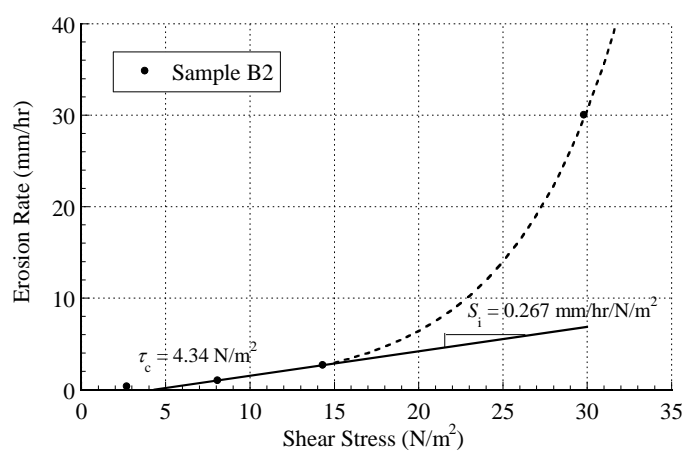

(f)

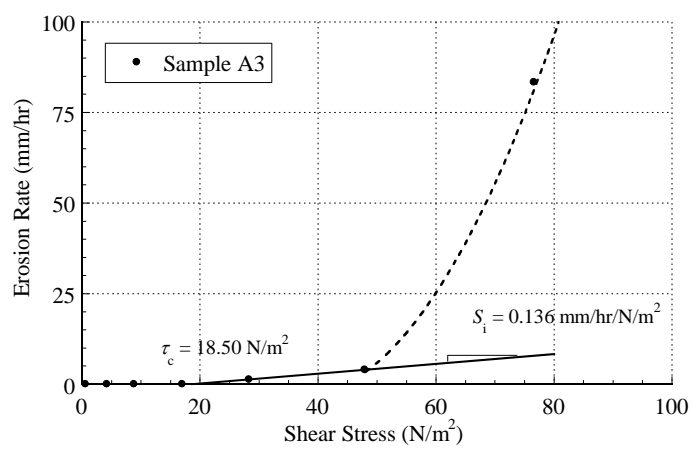

Figure 4. Erosions of three representative clays: unprotected clay (Sample A4), HPTRM-strengthened clay with poor grass cover (Sample B2), and good grass cover (Sample A3) in EFA: (a), (c) and (e) erosion classifications (Briaud et al., 2008) in terms of shear stress of unprotected clay, poor grass cover, and good grass cover, respectively; (b), (d) and (f) erosion function curve of unprotected clay, poor grass cover, and good grass cover, respectively, in the linear coordinate system (the solid line is the initial linear curve; while the dotted curve represents the possible erosion process after the lift up of HPTRM. $S_{\mathrm{i}}$ is the initial slope of the erosion rate vs. shear stress curve after $\tau_{c}$ ). 
(a)

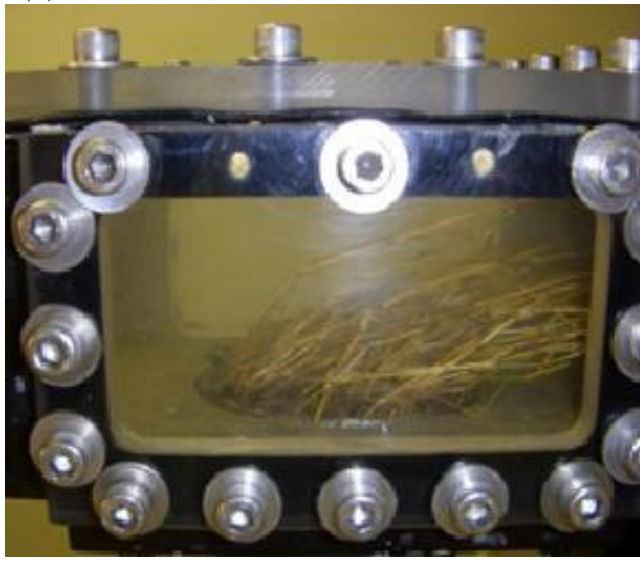

(b)

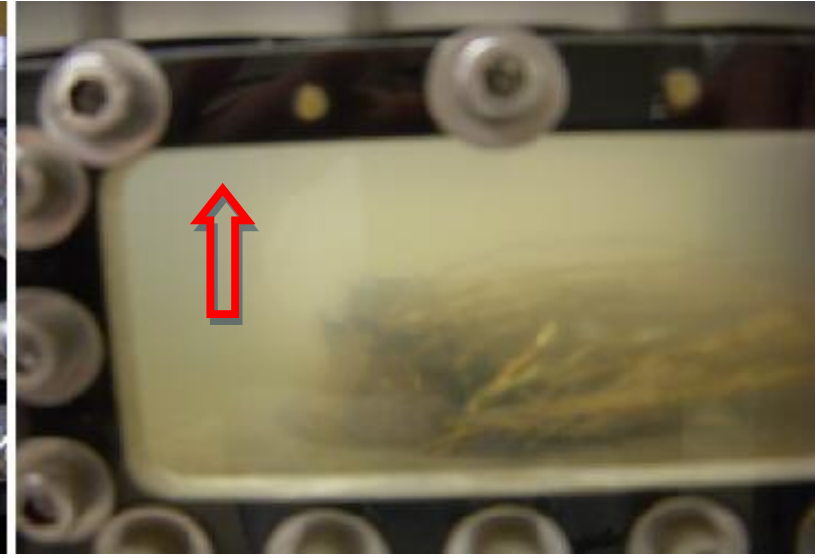

Figure 5. HPTRM-strengthened clay with good grass cover in EFA: (a) image for HPTRM not lifted up; (b) image for HPTRM lifted up. 
(a)

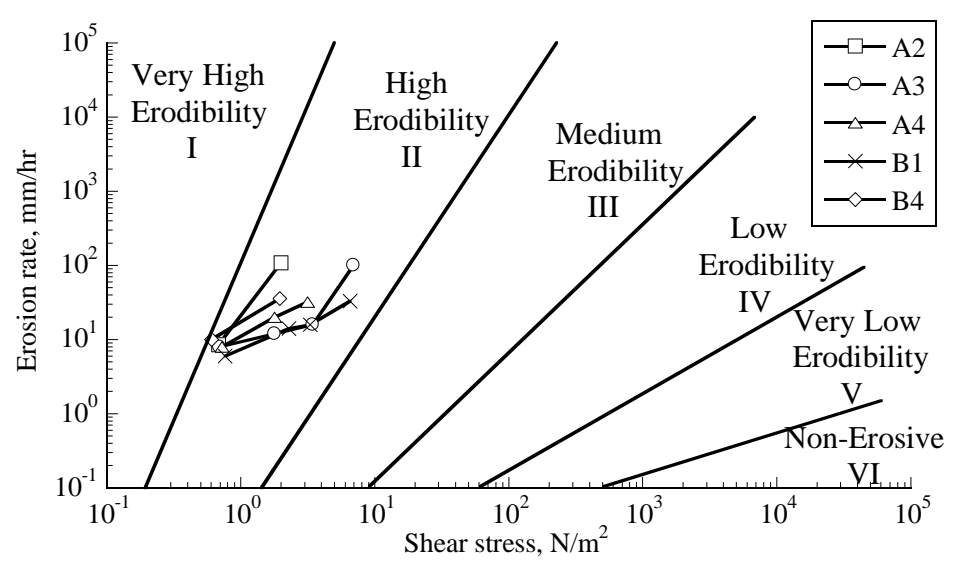

(b)

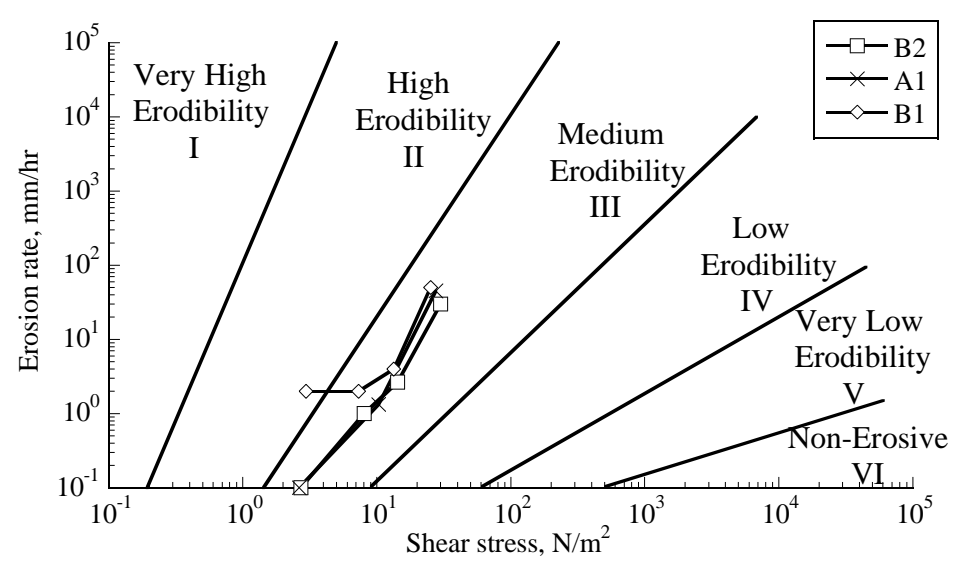

(c)

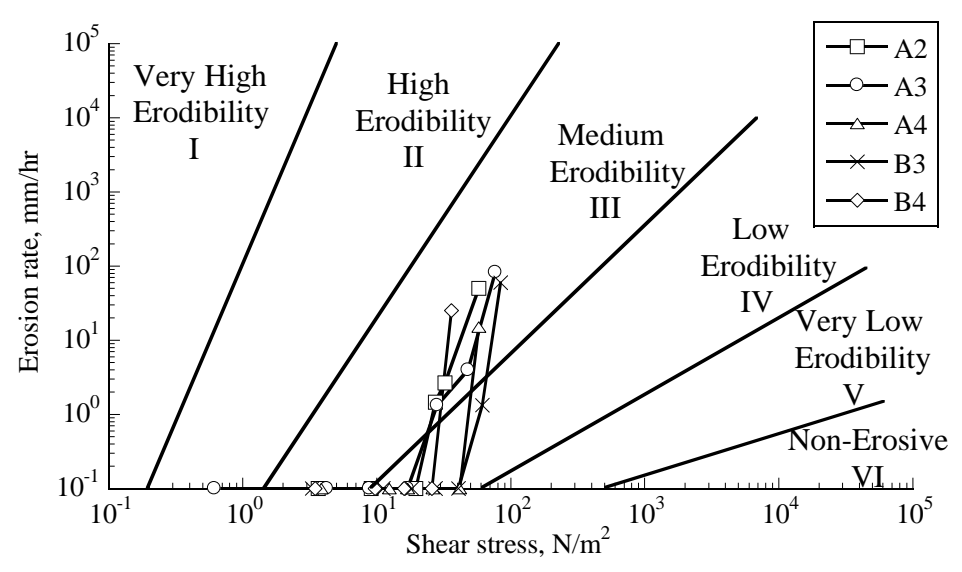

Figure 6. Erosion classification (Briaud et al., 2008) for all samples in terms of shear stress: (a) unprotected clays; (b) HPTRM-strengthened clay with poor grass cover; and (c) HPTRM clay with good grass cover. 

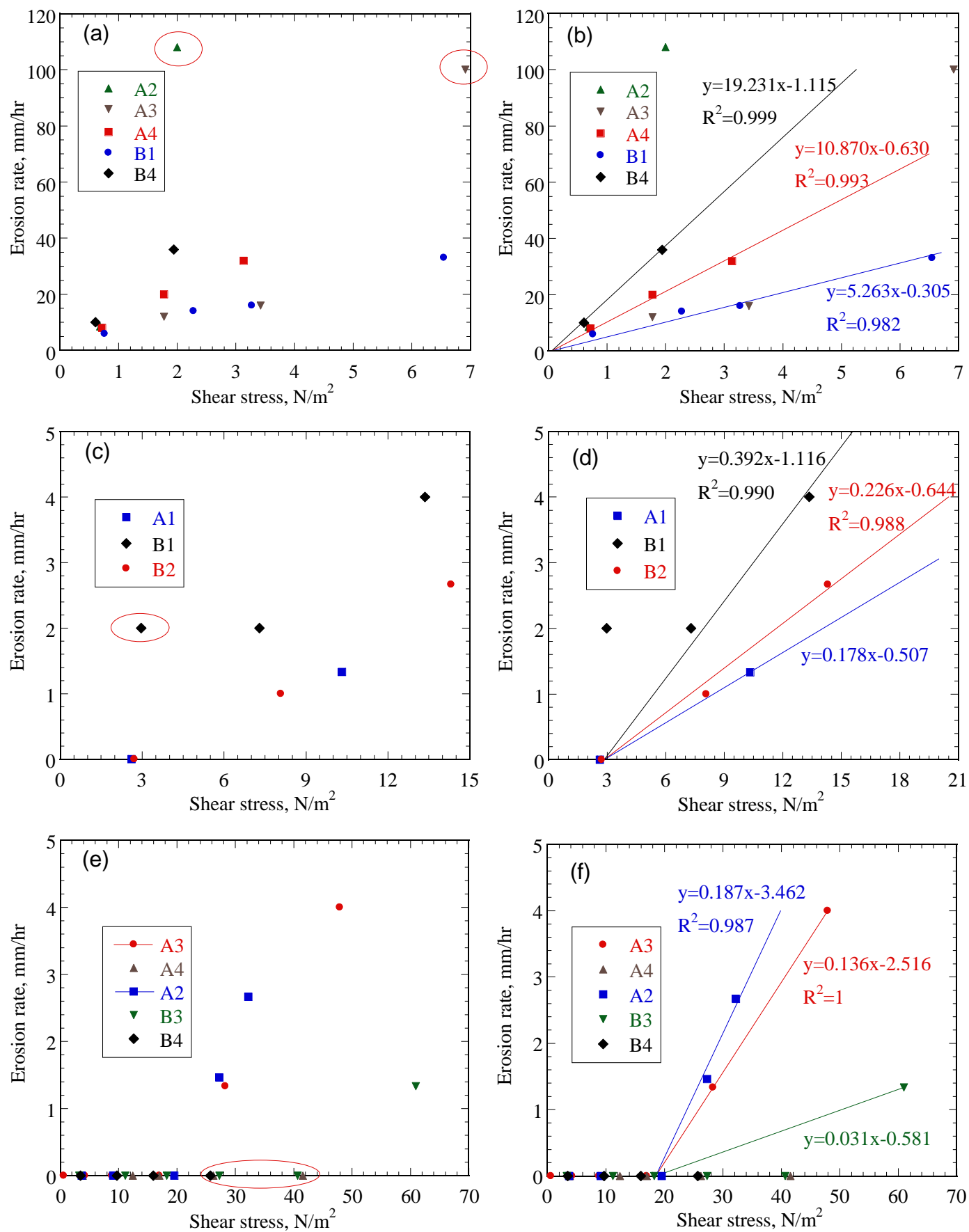

Figure 7. Erosion rate - shear stress plots for all samples in the linear coordinate system: (a) unprotected clays; (c) HPTRM-strengthened clay with poor grass cover; and (e) HPTRM-strengthened clay with good grass cover. Data after HPTRM's lift-up are excluded in (c) and (e) to clearly illustrate the erosion function of clay with protections. Circled points indicate the possible presence of errors caused by clay, observers and equipments: (a) clay may be eroded block by block; (c) erosion rate remains the same as shear stress increases, and this circled point alone goes across the boundary to "High Erodibility II" in Figure 6(b); (e) erosion less than $1 \mathrm{~mm} / \mathrm{hr}$ is difficult to measure due to the blockage of grass and mat. The critical shear stresses (the loadings when erosions start) are very close in each image. The averaged critical shear stress is used to draw best fits without circled points: (b) unprotected clays; (d) poor grass cover; and (f) good grass cover. Values of $\mathrm{R}^{2}$ are all close to 0.99 indicating shows very good linear relationships. 


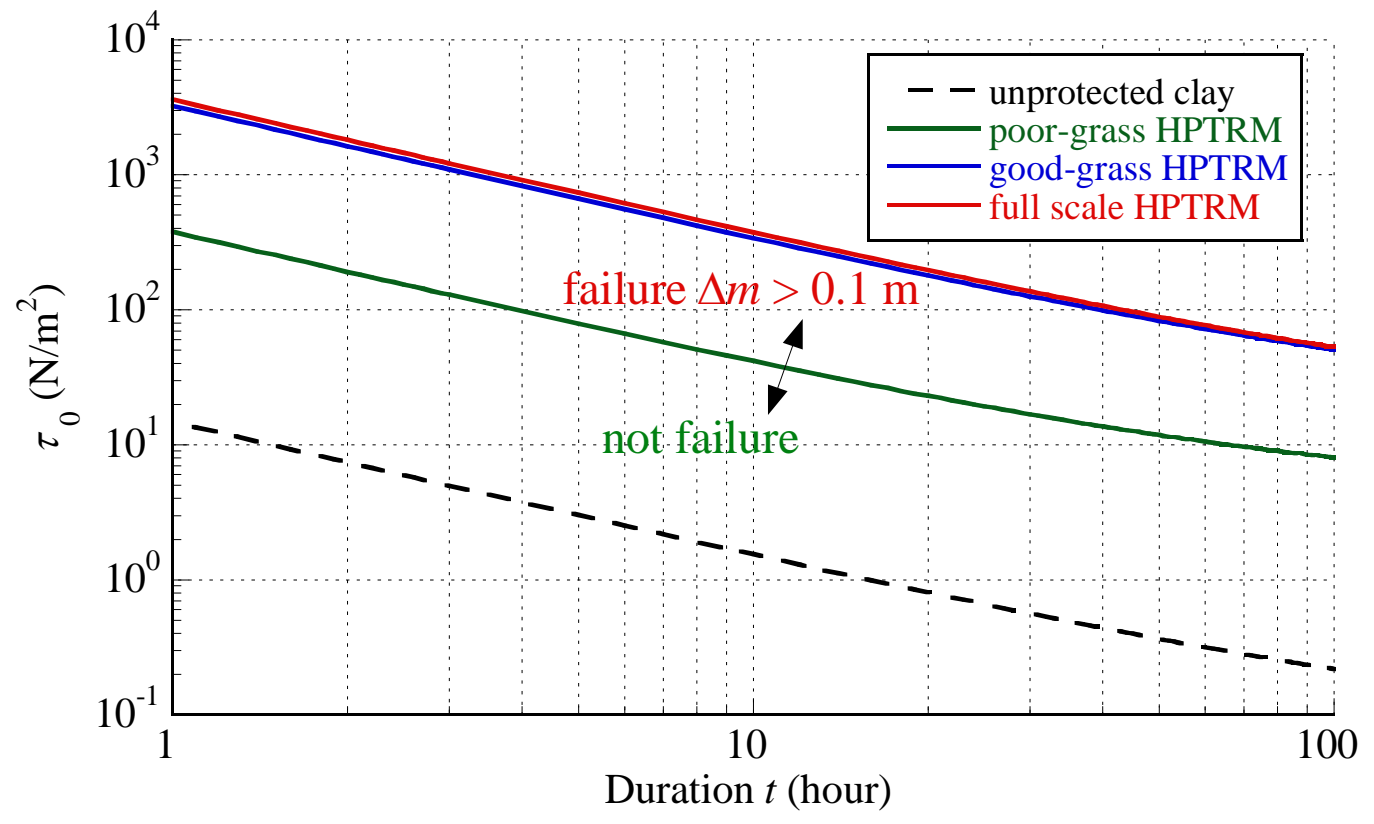

Figure 8. The relationships between bottom shear stress and duration. 


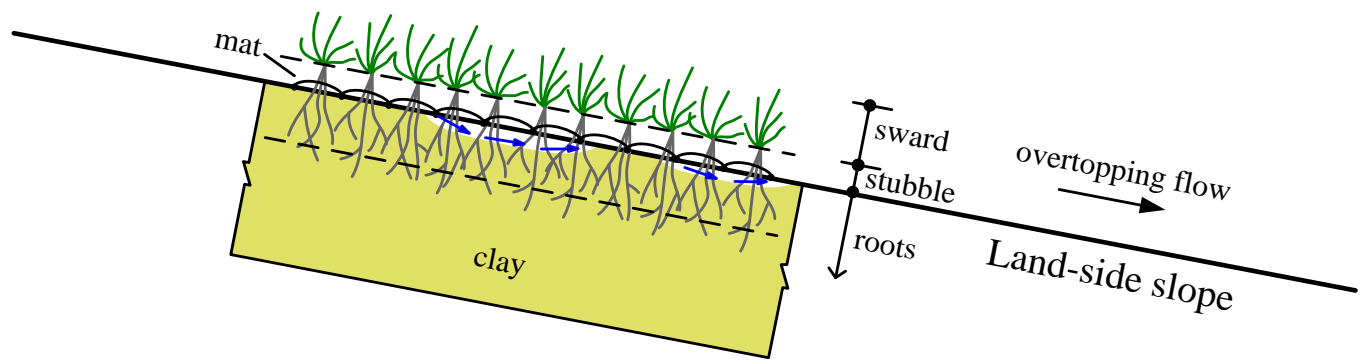

Figure 9. Shallow scours developing on the surface of HPTRM-strengthened slope under overtopping flow. 


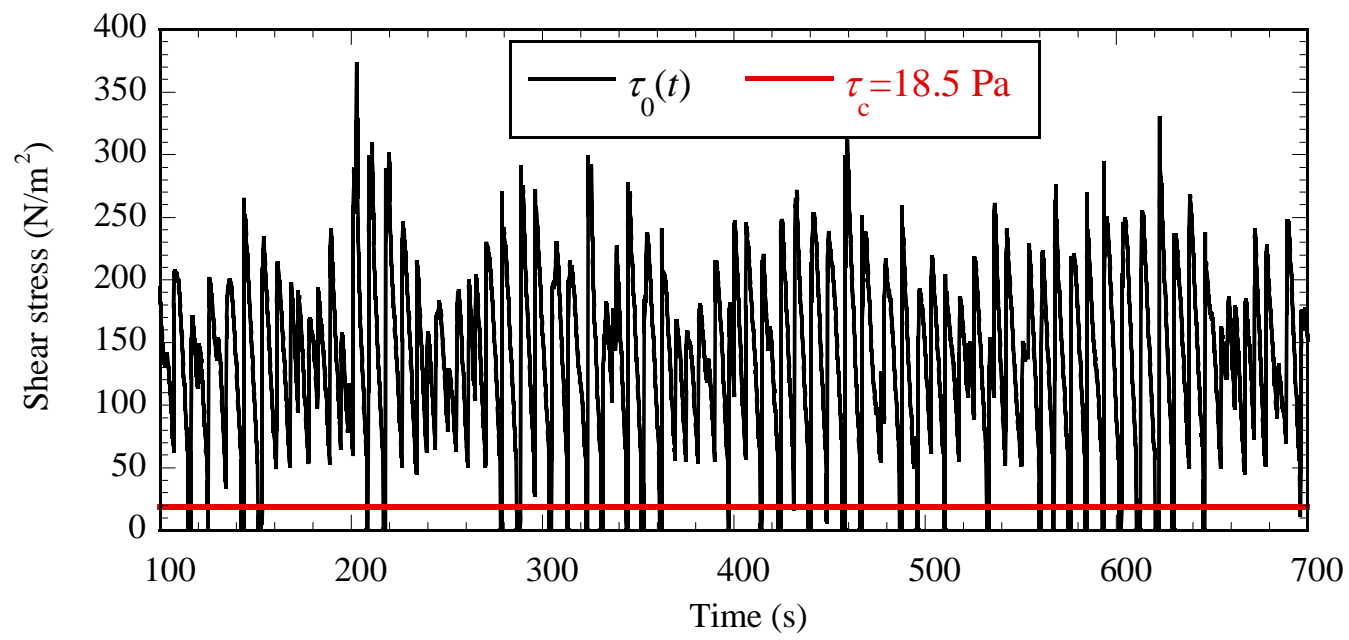

Figure 10. Time history of bottom shear stress at the toe of land-side slope $\left(R_{c}=-0.3 \mathrm{~m}, H_{m 0}=0.778 \mathrm{~m}\right.$, and $\left.T_{p}=7 \mathrm{~s}\right)$. 


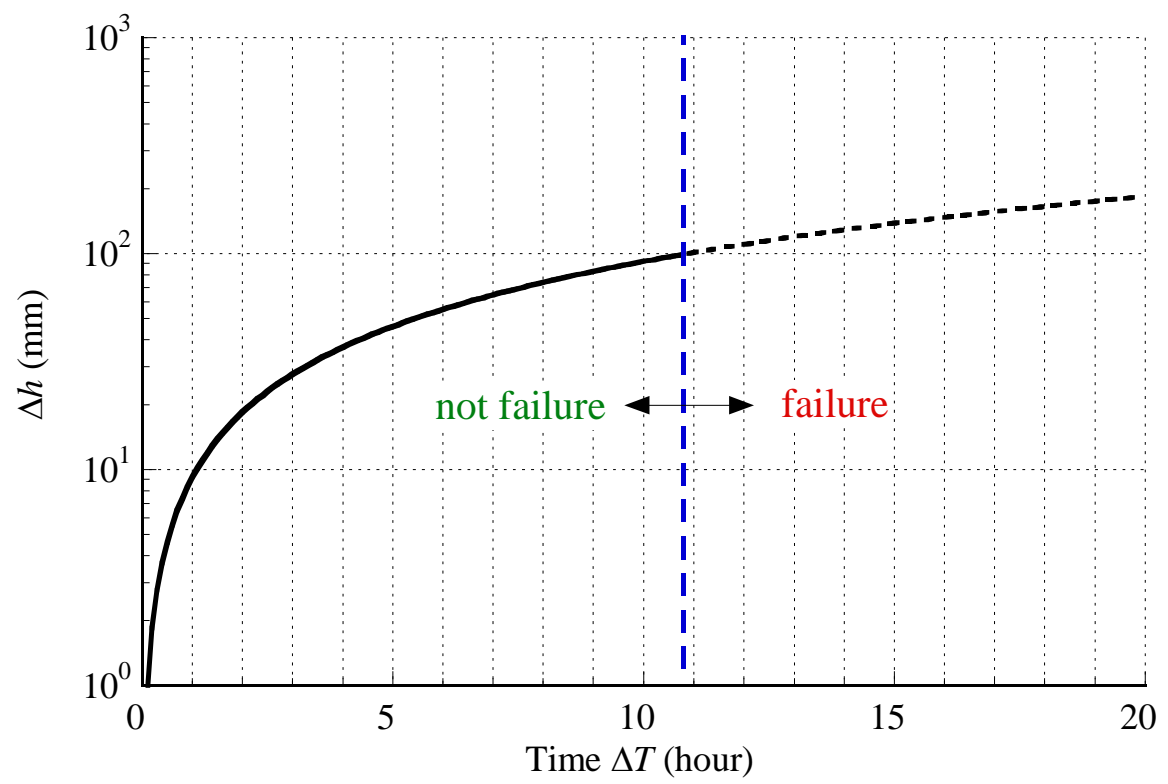

Figure 11. Time history of scour depth at the toe of land-side slope $\left(R_{c}=-0.3 \mathrm{~m}, H_{m 0}=0.3 \mathrm{~m}, \tau_{c, H}=18.5\right.$ $\mathrm{Pa}$, and $K_{d, H}=0.031 \mathrm{~mm} / \mathrm{hr} / \mathrm{N} / \mathrm{m}^{2}$ ). The dotted curve represents the unpredicted erosion process after HPTRM failure. 


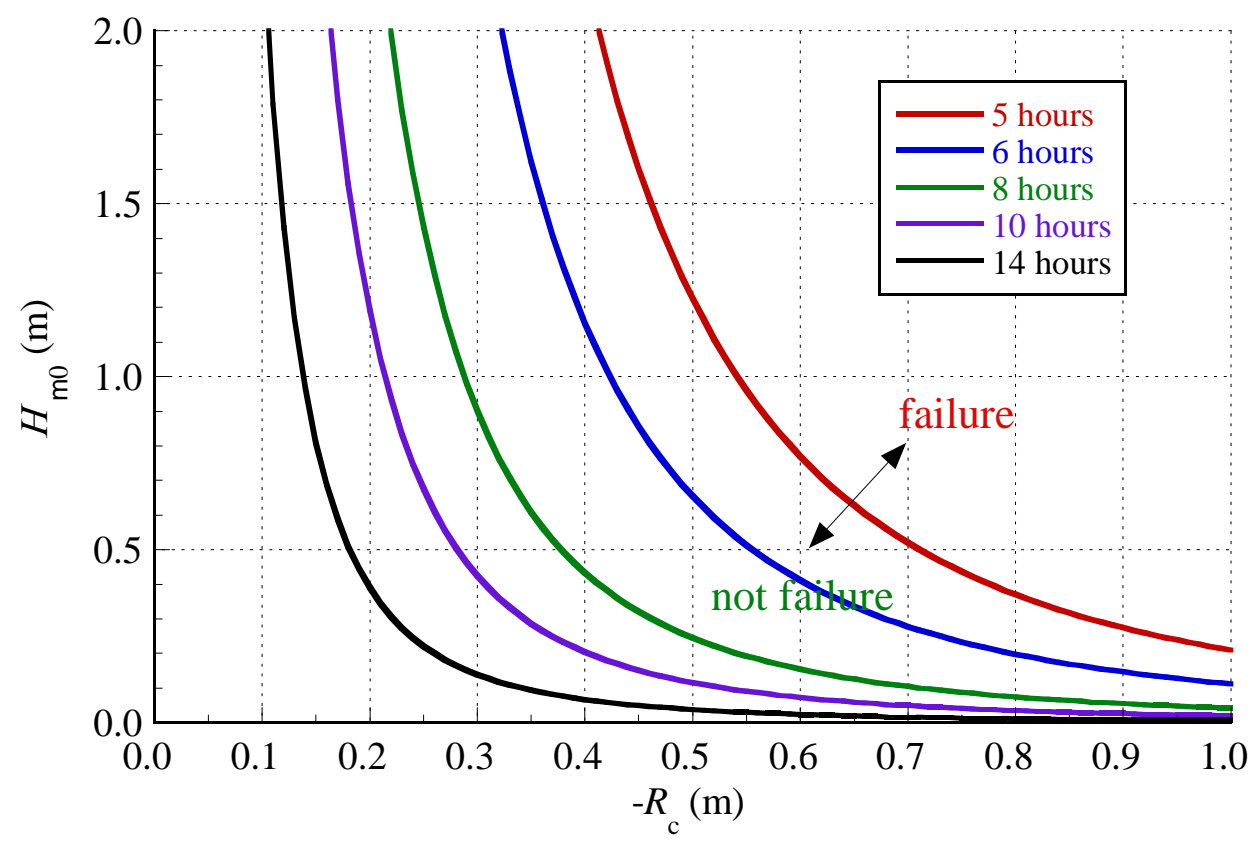

Figure 12. Overtopping conditions for different durations of HPTRM-strengthened levee. 

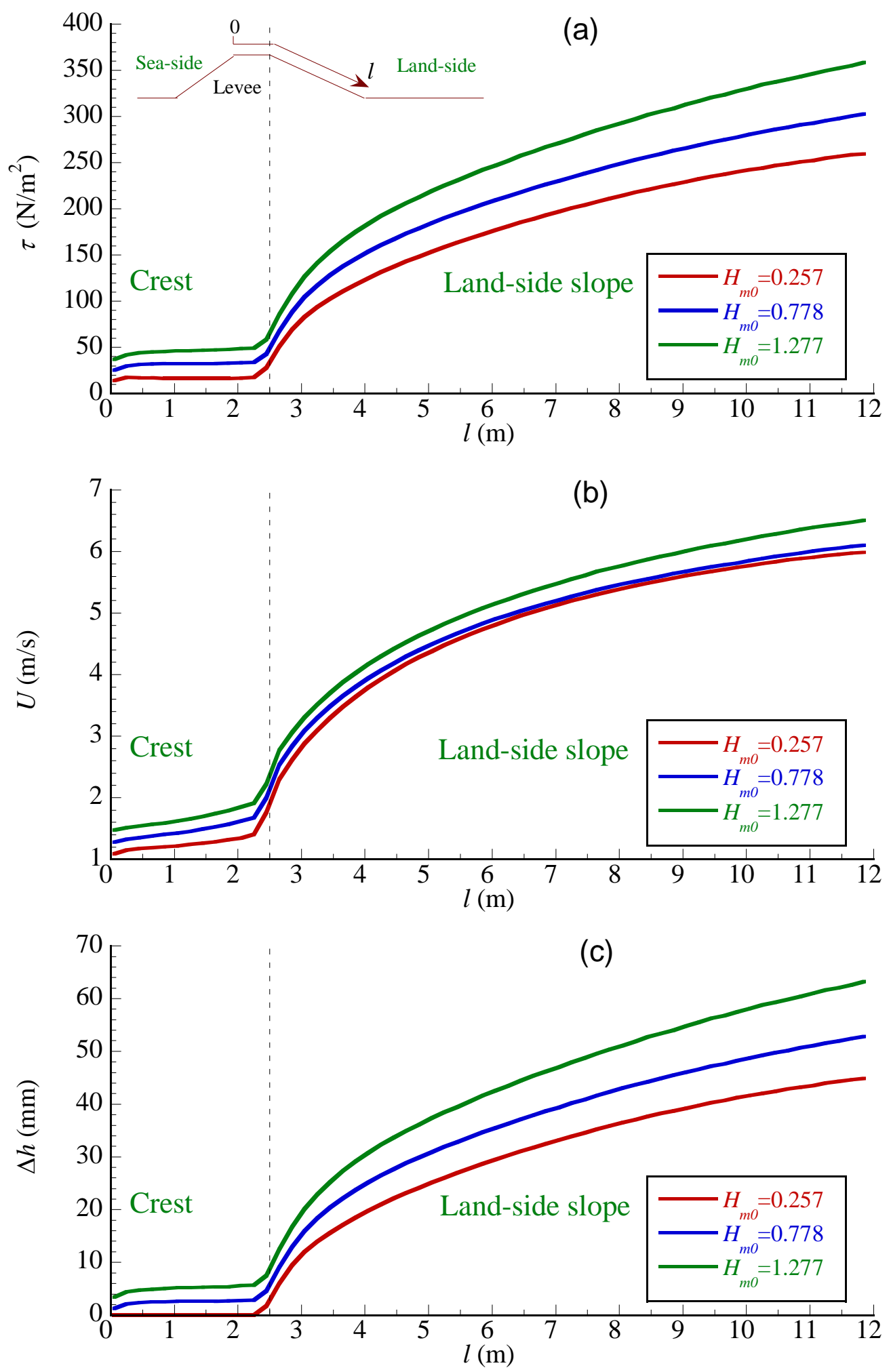

Figure 13. Profiles of time-average shear stress and velocity distributions along the top and slope of levee: (a) shear stress (b) velocity. (c) Erosion thickness after 6 hours calculated by Eq. (19), where $R_{c}=-0.3 \mathrm{~m}, \tau_{c, H}=18.5 \mathrm{~Pa}$, and $K_{d, H}=0.031 \mathrm{~mm} / \mathrm{hr} / \mathrm{N} / \mathrm{m}^{2}$. 


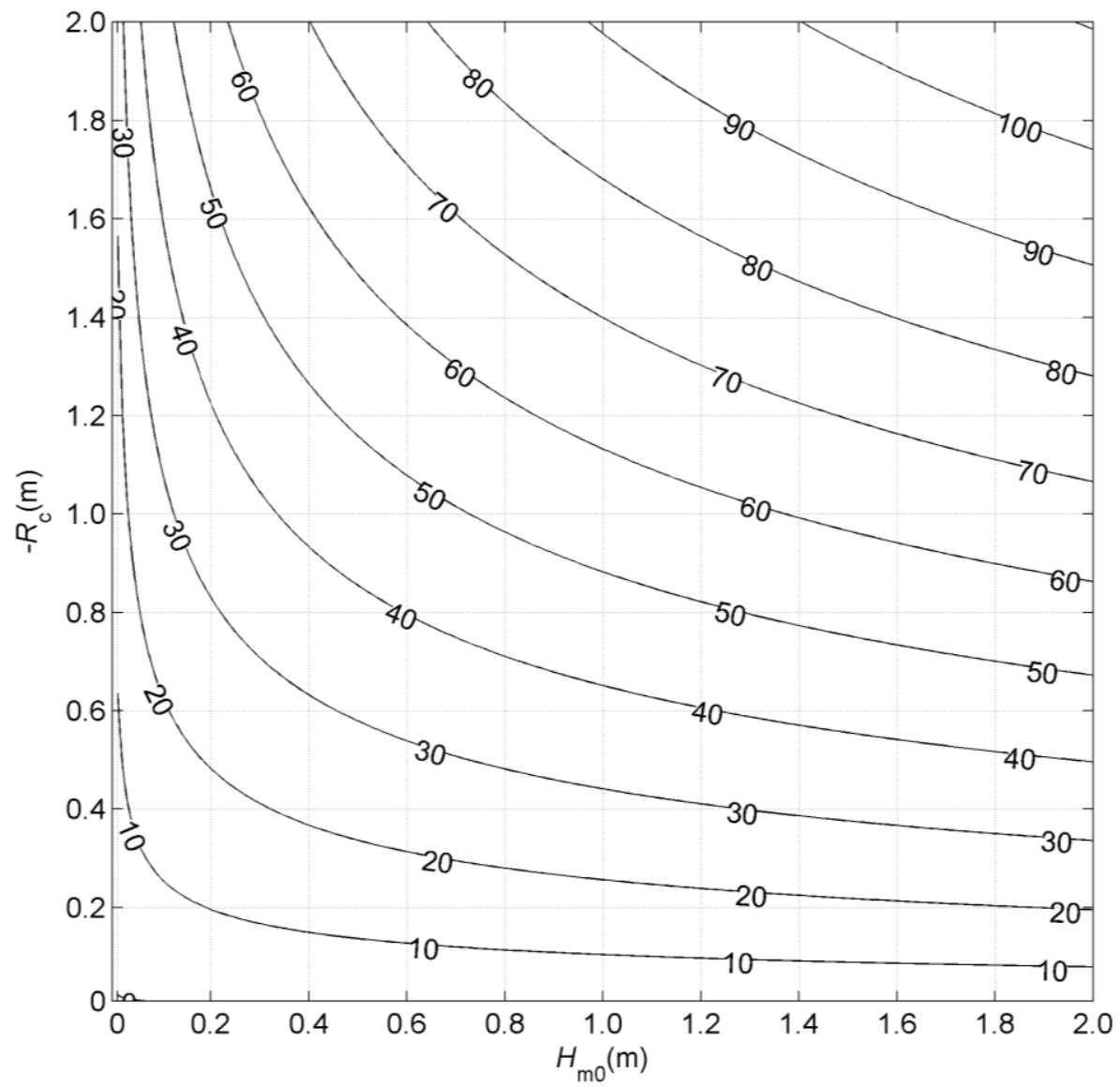

Figure 14. The values of $\left(\overline{\tau_{0}}-\tau_{c}\right) / \tau_{c}$ at the landside slope of HPTRM-strengthened levees under different combined overtopping conditions ( $\overline{\tau_{0}}$ is estimated by Eq. (20), and $\tau_{c}=18.5 \mathrm{~N} / \mathrm{m}^{2}$ ). 


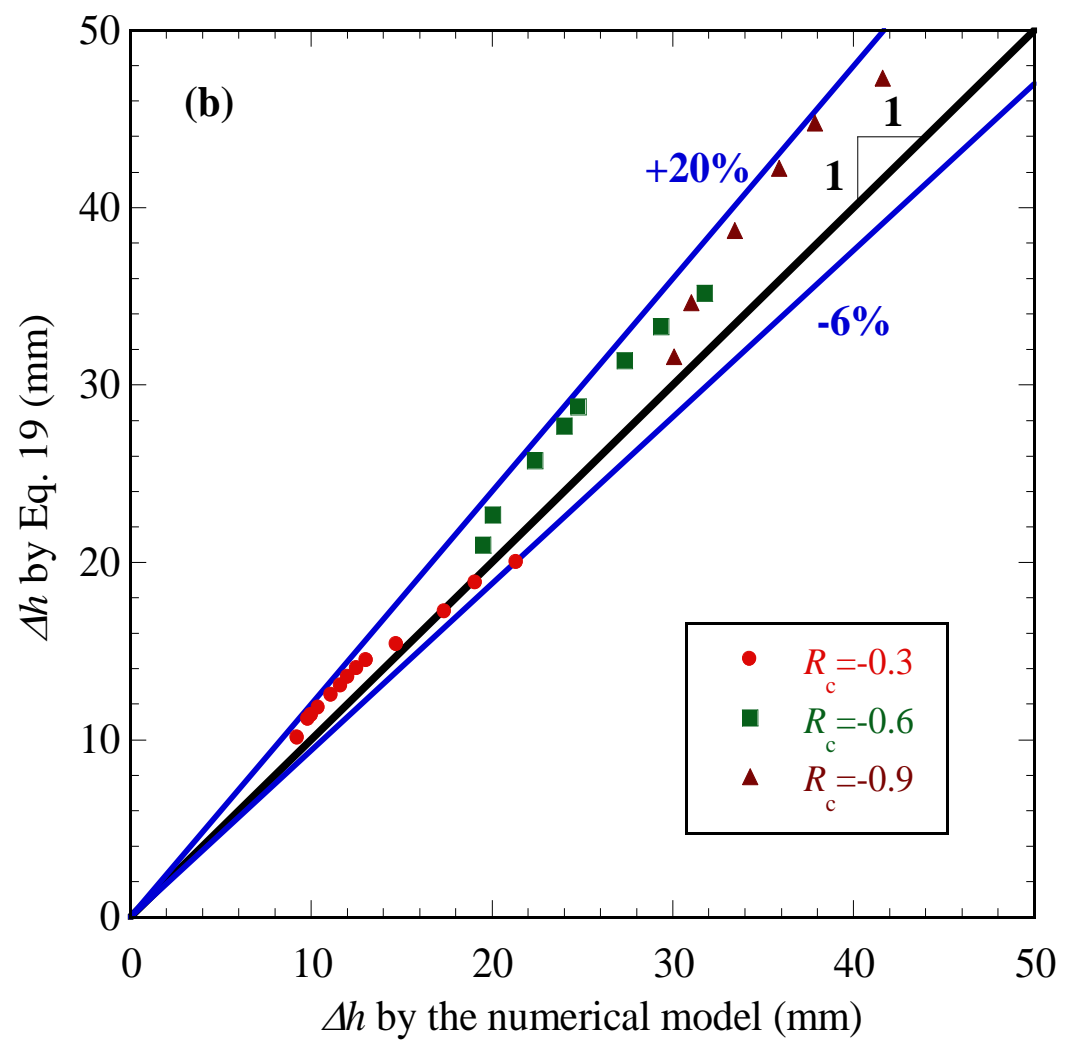

Figure 15. Validation of the proposed analytic equation $\left(\tau_{c, H}=18.5 \mathrm{~Pa}\right.$, and $\left.K_{d, H}=0.031 \mathrm{~mm} / \mathrm{hr} / \mathrm{N} / \mathrm{m}^{2}\right)$. 


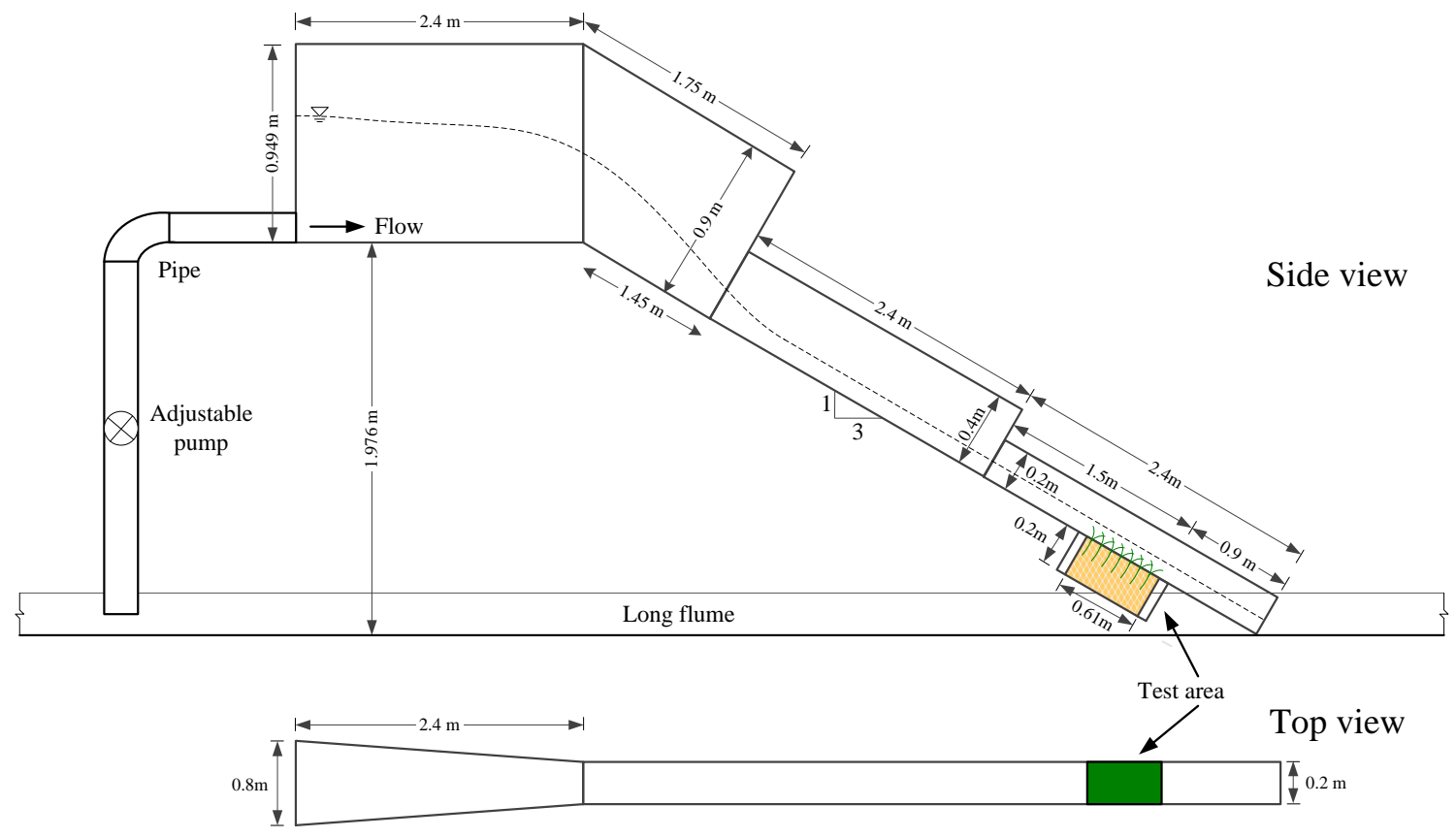

Figure 16. Experimental setup of EFA-similar tests (designed by co-author Dr. Pan) 


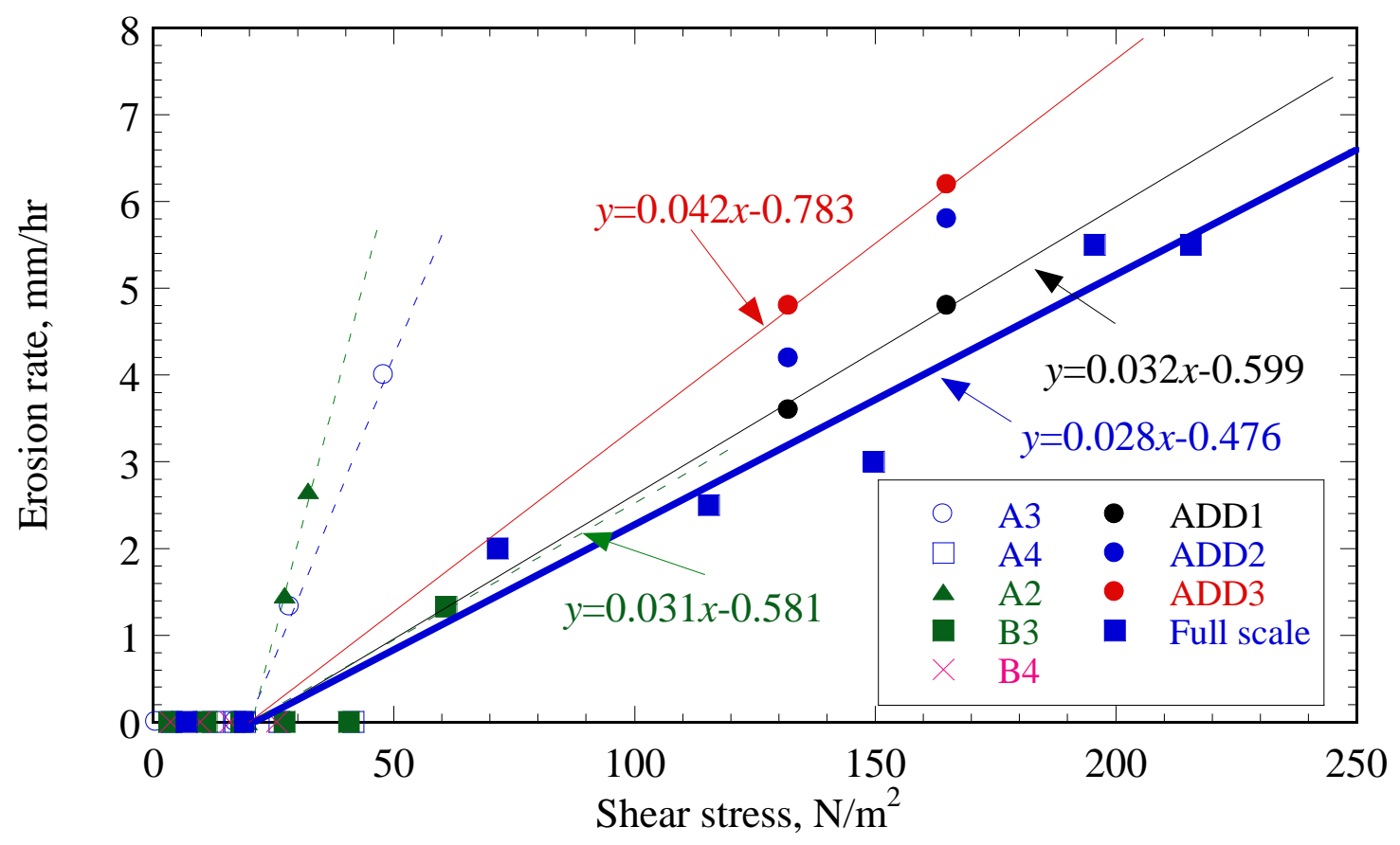

Figure 17. Comparison of EFA test results for HPTRM-strengthened clays, EFA-like test results (named ADD1, ADD2 and ADD3) and full-scale test results. 